\title{
Kernos
}

Revue internationale et pluridisciplinaire de religion grecque antique

17 | 2004

Varia

\section{Succession des âges et pragmatique poétique de la justice : le récit hésiodique des cinq espèces humaines}

\section{Claude Calame}

\section{(2) OpenEdition}

Journals

Édition électronique

URL : http://journals.openedition.org/kernos/1402

DOI : 10.4000/kernos. 1402

ISSN : 2034-7871

\section{Éditeur}

Centre international d'étude de la religion grecque antique

\section{Édition imprimée}

Date de publication : 1 janvier 2004

ISSN : 0776-3824

\section{Référence électronique}

Claude Calame, «Succession des âges et pragmatique poétique de la justice : le récit hésiodique des cinq espèces humaines », Kernos [En ligne], 17 | 2004, mis en ligne le 22 avril 2011, consulté le 01 mai 2019. URL : http://journals.openedition.org/kernos/1402 ; DOI : 10.4000/kernos.1402 


\section{Succession des âges et pragmatique poétique de la justice : le récit hésiodique des cinq espèces humaines}

Que n'a-t-on dit, que n'a-t-on écrit sur le "mythe hésiodique des races »? Insérant le poème didactique des Tiavaux d'Hésiode dans une temporalité et une spatialité spécifiques, ce récit en diction homérique constitue l'exemple même du texte qui anime et focalise périodiquement la controverse interprétative chez des philologues en mal d'objets nouveaux. À travers les différentes lectures qu'il a suscitées, cette centaine de vers épiques a été lue, à quelques exceptions près, comme un ensemble narratif autonome, coupé de son contexte (intra-)discursif, coupé aussi de sa situation d'énonciation. De discours le récit a été réduit à l'état de texte. La double interprétation structurale dont il a bénéficié dans les années soixante a largement contribué à ce double isolement, renforcé par la croyance moderne tenace dans l'existence d'un en-soi du mythe. À la faveur d'un contexte idéologique où l'on a souvent conféré aux concepts opératoires de l'anthropologie culturelle et sociale un statut d'universalité ontologisante, l'ouverture relativiste qu'aurait pu représenter la comparaison avec des versions orientales apparemment parallèles s'est en définitive révélée conduire à l'aporie. Or les créations narratives que nous appréhendons comme des «mythes » doivent être considérées, en particulier en Grèce antique, à la fois comme le résultat d'une fabrication poétique et fictionnelle à partir d'une réalité sociale et culturelle singulière, et comme des moyens symboliques destinés à agir sur une telle conjoncture historique. Dans une perspective sensible aux phénomènes énonciatifs renvoyant dans tout texte à une situation de communication qui en fait un discours, on aimerait proposer une relecture du régime de temporalité et de spatialité pratique institué, dans ses nombreux paradoxes, par le «mythe des races » dans le poème d'Hésiode consacré aux travaux et aux jours.

\section{Objet et méthode : de l'analyse structuriale à l'étude discur'sive}

On a donc peu à peu oublié, en pêchant en général par simple omission, toute une série d'évidences quant à la réalité discursive du «mythe hésiodique des races ».

En premier lieu, comme l'indique l'usage de la catégorie indigène dénommée au début même du texte (vers 106), ces vers ne représentent pas un "mythe ", mais un lógos; il s'agit donc d'un simple récit. Ensuite, en raison 
même de l'ordre chiffré de succession sous lequel ce lógos les présente, les géne ne sont pas des "races", mais ce terme renvoie à des générations d'ancêtres, c'est-à-dire à des groupes d'humains qui, au nombre de cinq, sont marqués dans chaque cas par une naissance et une extension spatiotemporelle particulières pour être organisés dans un ordre de succession linéaire; c'est pourquoi à mythe des races on substituera la désignation de récit des cinq familles ou de récit des cinq âges, voire de récit des cinq clans ou de récit des cinq espèces bumaines.

Par ailleurs, du point de vue énonciatif, le récit des cinq familles est fortement articulé, par l'intermédiaire de la forme du futur performatif ekkoruphóso ("je vais raconter jusqu'à son terme», vers 106), avec la narration du récit précédent; ces vers racontent, dans une version différente de celle offerte par la Théogonie, la création de Pandôra. De manière analogue, le lógos des cinq âges débouche, par l'entremise d'une forme performative semblable (eréo, « je vais dire », vers 202), sur la narration de la fable du rossignol et de l'épervier. De plus, cette séquence de trois lógoi s'inscrit dans le contexte intra-discursif plus large qui se déploie dans les vers précédant la série narrative : adresse aux Muses pour chanter Zeus et mettre en place l'isotopie de la justice et de la gestion du droit qui va traverser toute la première partie du poème; évocation de Persès puis adresse au frère prodigue, pour engager, par l'apologue des deux Érides, l'isotopie du travail productif (vers 10 et 27) qui sous-tend le développement sémantique de la seconde partie de la composition; allusion au conflit qui oppose le locuteur à son "allocuté » et qui peut être réglé par une sentence rétablissant sous le contrôle de Zeus l'équilibre du juste partage, avec l'engagement par l'énoncé de la sentence d'une troisième isotopie, celle de la parole poétique efficace ${ }^{1}$. Enfin, toujours sur le plan énonciatif, la séquence des trois récits débouche sur de nombreuses exhortations à Persès pour l'inviter à suivre la voie de la justice dans la cité; puis, dans un glissement énonciatif progressif à travers des invitations plus générales adressées en particulier aux rois, le poème des Travaux se focalise finalement sur la production de la prospérité que sont censés provoquer les conseils prodigués.

Tout en assurant la cohérence de l'ensemble de la composition, la tournure polymorphe de ces différentes adresses et interventions énonciatives, par des procédures sur lesquelles on aura à revenir, pose la question du genre auquel appartient ce poème en diction épique; et les règles de genre qui organisent cette composition héroïque conduisent elles-mêmes en définitive, dans un passage de l'intra- à l'extra-discursif, à s'interroger sur les circonstances d'énonciation et sur sa fonction! Susceptible d'éviter les lacunes interprétatives mentionnées, l'attention aux marques de l'énonciation que propose l'analyse des discours devrait nous permettre de dessiner le régime de temporalité (et de spatialité) qui fonde le récit des âges tel qu'il est déployé dans les

1 Les trois isotopies atticulant le contenu des Travaux en trois lignes de développement sémantique entrelacées ont été définies clans mon essai (1996b), où l'on trouvera de nombreuses références à différentes études illustrant ce propos. La présente étude s'inscrit dans une recherche plus vaste sur différents régimes de spatio-temporalité pratique en Grèce antique. 
Travaux tout en illustrant les effets discursifs et poétiques d'une configuration spatio-temporelle d'ordre didactique. Par un bref retour comparatif sur ce qui est devenu le paradigme sémitique, il s'agira de s'interroger en conclusion sur les fonctions intra- et extra-discursives d'une représentation poétique d'un temps passé orienté vers le futur, avant d'en tirer l'une des leçons possibles dans le contexte de la postmodernité.

La controverse interprétative suscitée par la lecture du récit héroïque des âges dans la seconde moitié du $x x^{e}$ siècle a été fortement marquée par les principes de l'analyse structurale.

C'est au philosophe de l'Antiquité Victor Goldschmidt que l'on doit d'avoir rompu avec la lecture traditionnelle d'un récit censé rendre compte de la décadence progressive d'une humanité peu à peu livrée au règne de l'injustice, en imposant le paradigme structural. La brillante idée française d'une narration où le dessin d'une ligne génétique viendrait établir une structure statique permet de montrer que la succession des "races » dans leur déclin conduit à l'ordre hiérarchique qui assigne des places distinctes aux dieux, aux démons, aux héros et finalement aux morts. En reprenant cette lecture du récit hésiodique, Jean-Pierre Vernant a systématisé dans le sens structural la fonction en effet fondatrice d'un "mythe » qu'il considère comme "généalogique » : saisi en synchronie, l'ordre différencié final n'est que la résultante de la naissance successive, dans la diachronie narrative, des entités qu'organise la structure. Conclusion en ce qui concerne le récit hésiodique des âges : «La succession des races dans le temps reproduit un ordre hiérarchique permanent de l'univers $»^{2}$.

Mais à la perspective structurale s'ajoute l'analyse structurale elle-même; cette dernière postule que les valeurs faisant système s'organisent en une séquence ou une hiérarchie d'oppositions binaires. De là la réorganisation interprétative du "mythe des races" en une succession de trois couples de géne s'opposant symétriquement l'une à l'autre selon une opposition structurale érigée en un trait sémantique distinctif : dikke / buibris, soit «justice »/ «violence ». Dans une telle perspective herméneutique, les hommes d'or représentent l'envers des hommes d'argent dans le domaine de l'exercice de la souveraineté; la violence brutale de la race de bronze s'oppose à la justice courageuse des héros dans le domaine de l'activité militaire; quant à l'âge de fer, il est lui-même divisé de manière structurale en deux périodes contrastées de justice et de déclin du point de vue de la productivité du travail agricole. Par la réorganisation de la diachronie en synchronie, la structure finit par s'insérer dans le modèle des trois fonctions attribué aux Indo-européens. Nombreux furent dès lors les efforts tendant à éviter les différentes distorsions

2 Goldschmidt (1950), p. 33-38 (réunion de deux traditions différentes, le «mythe des âges» et le récit de la «division des êtres divins» dont le premier devient le mythe étiologique du second), dans une analyse reprise par VernANT (1960), p. 24-30 (25 pour la citation); pour les détails de la controverse suscitée par ces tentatives d'application des principes de l'analyse structurale avec les précisions apportées dans chaque cas pour les deux auteurs cités, voir Couloubaritsis (1996), p. 479-485 (avec les références données n. 7). 
de lecture impliquées par la coincidence établie entre la succession diachronique des oppositions structurales et l'architecture synchronique de l'idéologie tri-fonctionnelle. Ces tentatives se sont en général limitées à des modifications de l'économie arithmétique du schéma structural : "Or us Argent (référence utopique) / Bronze et Héros 1 us Héros 2 (référence homérique) / Fer 1 us Fer 2 (référence politique)», ou «âge d'Or - âge d'Argent - âge de Bronze (processus de déchéance) / âge des Héros (redressement) / âge de Fer 1 âge de Fer 2 - âge de Fer x (nouvelle déchéance, avec espoir de redressement) », ou encore " or - argent/bronze - héros (organisés en une tétrade qui clôt sur lui-même, en chiasme, le processus de décadence puis d'amélioration) / race présente (fer) $»^{3}$.

Parmi ces trois tentatives de concilier le principe de la genèse aboutissant à la structure avec les «anomalies » d'un texte qui introduit par exemple les héros dans une séquence d'âges métalliques, le dernier modèle mentionné présente un avantage décisif; en effet, il tient compte du statut singulier qu'assigne à l'âge de fer sa présentation énonciative particulière. Sans en tirer à vrai dire toutes les conséquences nécessaires, on n'a pas manqué de remarquer récemment que l'introduction du dernier âge était marquée par une forte intervention énonciative du locuteur ou narrateur, un locuteur-narrateur que l'on a de bonnes raisons d'identifier avec Hésiode'. Dans ce passage de l'« histoire " (ou du « récit») au «discours», ce sont à la fois le temps narré et le temps de la narration du récit des cinq familles qui viennent coïncider avec le temps de l'énonciation énoncée et par conséquent avec le mouvement même de l'énonciation du poème. Ce moment est repéré dans l'énoncé même par l'insertion forte et du je du locuteur-narrateur (vers 174) et du nûn (vers 176) qui réfère temporellement le génos de fer au moment présent.

En abandonnant le paradigme structural qui impose des divisions artificielles dans le but de reconstruire des oppositions binaires, il est essentiel de suivre le déroulement spatio-temporel du récit. Au-delà du simple temps raconté, l'attention se portera à la fois sur la temporalité de la narration impulsant son rythme propre à la succession des âges et sur le temps et l'espace de l'énonciation énoncée, marqués par les interventions du locuteur-narrateur notamment dans les adresses aux différentes figures occupant la position de l'«allocuté »: Persès, les rois ou un tu générique 5 . On sera donc attentif aux lignes temporelles et spatiales qui organisent le récit en lui conférant sa logique et sa cohérence. Une telle perspective s'impose à d'autant plus forte

3 On a cité, dans l'ordre, les interprétations de Carràre (1996), p. 419, de Couloubaritsis (1996), p. 517-518, et de Crubellier (1996), p. 453.

4 C'est le mérite de NESCHKE (1996), p. 473-477, de l'avoir montré; voir aussi CrubFLLter (1996), p. 440-442, MOST (1997), p. 111-114, et Sourvnou-InwoOd (1997), p. 4-5. La lecture pertinente de Neschke a pour conséquence l'organisation des âges en deux triades : or / argent / bronze d'une part, héros ( $a v a n t$ nous ») / fer ( maintenant )) / fer 2 " phase ( a après nous $»$ ), d'autre part. L'identification du locuteur-narrateur avec Hésiode est soufflée à l'auditeur / lecteur par les vers 22-25 de la Théogonie.

Pour le triple destinataire des Travaux; voir CALAMF (1996)), p. 174-181 (avec n. 29). Structure d'ensemble du poème : HamLton (1989), p. 47-84. 
raison que, d'une part, le "mythe des races » n'illustre que très partiellement le principe de l'explication de la structure par la genèse et que, d'autre part, il ne constitue pas un véritable récit généalogique où l'ordre taxinomique final naîtrait de l'engendrement progressif des différentes entités qui le composent. En effet, les hommes de bronze, par exemple, disparaissent à tout jamais dans l'Hadès et ils n'assument aucune fonction sous la lumière du soleil dans le nûn énonciatif; ils n'existent plus au moment où le locuteur situe sa parole poétique.

De plus, contrairement au principe qui anime le récit généalogique où une troisième entité naît de l'union de deux entités premières, les géne sont créés par un dieu tout-puissant qui ne les inscrit pas dans un système caractérisé par l'arborescence généalogique. Les groupes d'humains se substituent donc les uns aux autres dans un ordre chronologique qui est l'objet d'un comput précis. C'est dire que les géne ne correspondent pas à des « races», mais elles représentent des ensembles de générations d'hommes, des « espèces humaines » ou plus exactement des groupes d'ancêtres ${ }^{6}$. C'est pourquoi à race, il est préférable de substituer - comme on l'a déjà suggéré - les termes de famille, de clan, d'espèce, voire d'âge si l'on tient compte de l'aspect chronologique de la succession des cinq groupes.

\section{Déroulement narratif : énonciation et argumentation}

Avant de se concentrer sur la structure du récit lui-même, avant de reprendre la question de son contexte narratif, puis celle de son éventuelle référence extra-discursive, il convient de s'interroger brièvement sur sa présentation énonciative et sur son insertion argumentative dans le contexte poétique immédiat. Comme on vient de le rappeler, le récit des cinq familles d'humains se situe entre le récit de la création de Pandôra (vers 42-105) et lá fable du rossignol et de l'épervier (vers 202-122); il s'insère ainsi dans une triade narrative qui est fortement articulée (gâr, vers 42) avec le premier développement sur les deux rivalités et sur la nécessité de régler le conflit judiciaire (ténde dikeñ , vers 39) entre le poète et Persès. Cette dimension argumentative relève moins de la double temporalité, narrative et narrée, du récit que de l'énoncé de l'énonciation du poème dans lequel est inséré le lógos des cinq âges. Elle marque les trois vers de prélude au récit (vers 106-108).

Si tu le veux bien, moi je m'apprête à achever un autre récit grâce à mon savoir-faire; quant à toi retiens dans ton esprit

comment les dieux et les hommes mortels partagent la même origine

La déclaration d'intention du locuteur-narrateur quant au récit dont il va tirer la substance est assortie d'une allusion au savoir technique du poète. Sous forme adverbiale (epistaménos, vers 107) ou adjectivale, ce savoir-faire correspond à celui d'Ulysse, qui sait raconter comme un aède, à celui du serviteur et messager des Muses qui, évoqué par Théognis, détient une

\footnotetext{
${ }^{6}$ Quant à la distinction sémantique entre génos et geneé, ç. iṇira n. 26.
} 
sagesse qu'il lui appartient de partager dans une perspective didactique, ou à celui du poète Solon qui, bénéficiant des dons des Muses, connaît « la mesure de la sagesse séduisante » (bimertês sophies métron epistámenos). Le lógos proféré est bien celui d'un sage, par référence au savoir du poète homérique ou mieux encore par allusion au savoir-faire du poète élégiaque, avec sa visée didactique et pédagogique coïncidant avec l'intention poétique - on le verra qui anime les Travaux.

Dès lors le fameux vers 108, qui donne un contenu au lógos à venir en assignant aux dieux et aux hommes une ascendance partagée, pourrait être "authentique ». En tant que complément à la recommandation adressée à Persès de bien enregistrer le lógos dit par le poète, ce vers aurait pour rôle d'indiquer, comme dans tout prélude, le thème du récit à suivre: colère d'Achille pour l'lliade, tribulations d'Ulysse pour l'Odyssée, naissance des dieux immortels pour la Théogoniè ${ }^{8}$. Le récit des âges tel qu'il est déployé dans les Travaux serait centré sur la question de l'origine commune des dieux et des mortels; ceci en accord avec le vers 59 qui présente Zeus comme le père des hommes et des dieux, et en harmonie avec le vers 112 qui accorde aux hommes du génos d'or un mode de vie semblable à celui des êtres divins. C'est une question sur laquelle on reviendra.

Enfin, le récit des cinq familles humaines est non seulement fortement lié au récit de la création de Pandôra qui le précède et à la fable du tossignol et de l'épervier qui lui fait suite, comme l'indiquent sa présentation en tant que second récit (béteron lógon, vers 106) et la reprise d'un futur performatif (eréo, vers 202) pour présenter l'ainos. Mais la séquence des trois récits est elle-même rattachée par le gâr argumentatif déjà signalé (vers 42) au premier développement du poème, consacré au conflit présent qui oppose le locuteur-narrateur à son destinataire principal, Persès. Cela signifie que, logiquement, la triade narrative constitue la première partie de l'argumentation visant à rétablir l'équilibre de la dike, c'est-à-dire à résoudre la dispute avec le frère prodigue. La forme énonciative assumée par le groupe de vers qui précède le triple récit est sans ambiguité : il s'agit de trancher maintenant, par une forme de l'impératif subjonctif qui à la première personne du pluriel inclut le je et le tu (diakrinómetha, vers 35), la rivalité qui nous oppose; ce sera l'effet de l'une de ces sentences droites qui proviennent de Zeus. Ce faisant, on écartera les rois "mangeurs de présents» qui entendent régler (dikásai, vers 39) « cette » cause (ténde dikenn), c'est-à-dire à la fois le procès dont on vient de parler et la cause présente - dans la double procédure de deixis anaphorique et monstrative, intra- et extra-discursive décrite par le linguiste Karl Bühler : combinée avec la deixis am Phantasma, lá demonstratio ad oculos peut référer aussi bien à ce qui vient d'être dit ou ce qui va être

\footnotetext{
${ }^{7}$ HOM., Od. XI, 368; Thgn., 769-772; SOL., fr. 1, 51-55 Gentili-Prato.

${ }^{8}$ On trouvera tous les détails de la controverse suscitée par le vers 108 , qui est commenté dans les scholies, chez CARrièrf (1991), p. 63-72. Pour la structure des préludes aux poèmes homériques, voir notamment PUCCI (1998), p. 11-29.
} 
dit dans le discours qu'à la réalité présente sous le regard de qui parle?. Cela signifie que du point de vue sémantique les trois récits répondant à cette intention poétique d'ordre performatif sont destinés à reprendre les trois isotopies développées dans le prélude et dans la première partie du poème des Travaux, à savoir - je le répète - la ligne sémantique de l'équilibre de la dỉke assortie dynamiquement de la nécessité poétique d'en rétablir l'équilibre; la ligne thématique du bíos, c'est-à-dire de la production des ressources de vie qui forment les conditions de cette réalisation de la justice dans la cité; enfin la ligne de la parole (poétique) proférée et de son efficacité, en particulier dans le domaine de la dike...

\section{Structures spatio-temporelles}

Du «maintenant » de l'adresse réitérée à Persès, le bref proème du lógos des cinq âges nous fait passer sans autre transition au récit lui-même. Du temps et de l'espace du « discours » avec la recommandation au destinataire d'accueillir en bel esprit la parole (poétique) proférée, on passe donc au temps et à l'espace de l'« histoire ». En coïncidant ici avec le début du temps narré, le développement initial du temps de la narration indique fortement quel est le moment axial, le moment de l'origine de la temporalité narrative. En effet l'adresse prótista ( en tout premier », vers 109) donne d'emblée une origine au passé où la forme de l'aoriste situe la création (poíesan, vers 110) du premier génos des hommes «terrestres » (méropes, vers 109). Par le temps de la narration, la ligne temporelle racontée reçoit ainsi un repère d'ordre chronologique, d'ordre «calendaire », dirait Benveniste.

Ce moment de l'origine a un nom : c'est le règne de Cronos; il a un lieu : c'est l'Olympe. Cette procédure d'engagement du récit selon les paramètres du temps et de l'espace n'est pas sans rappeler celle qui marque la conduite narrative de certains Hymnes bomériques. Après le prélude qui présente l'arrivée du jeune Apollon dans la demeure de Zeus, l'aède de l'Hymne à Apollon s'interroge sur la manière dont il va faire l'éloge hymnique d'une divinité aussi largement chantée que le dieu Phoibos; le récit commencera par le commencement, c'est-à-dire par la naissance du dieu à Délos; un commencement à la fois temporel et spatial.

Comment vais-je te chanter toi qui est célébré par tant d'hymnes?

Partout l'usage veut, Phoibos, que l'on te dédie des chants,

sur le continent qui nourrit des génisses comme dans les îles (...).

Dirai-je comment Létô d'abord t'engendra, joie pour les mortels,

s'appuyant sur le Mont Cynthe en l'île de Délos entourée par les flots ?"

'La tournure énonciative de ce groupe de vers est explicitée dans mon analyse (1996b), p. 178-181; sur les deux modes de la demonstratio ad oculos en contraste avec la Deixis am Phanlasma, voir BüHler (1934), p. 79-82, 107-140 et 385-392.

10 Hymn. Apoll., 19-21 et 25-27; voir aussi 207-216. Pour le sens du terme méropes, cf. infia $\$ 3.1$ avec n. 13. 
La relation syntaxique entre la question $p \underline{o} s$ au vers 19 et l'adverbe relatif (hymnique) bós au vers 25 met en rapport la forme du futur performatif bumnéo ( je vais chanter ») non seulement avec la première forme verbale du récit (téke, « elle engendra »), mais aussi avec le repère temporel de l'origine (prốton, "tout d'abord») et avec son repère spatial (Délos). Ainsi, par l'intermédiaire de l'habituelle procédure du relatif hymnique et sous la forme d'une interrogation rhétorique, le temps de l'énonciation énoncée (le futur immédiat et intentionnel de la récitation du poème), et le temps de la narration viennent coïncider avec le moment axial du temps raconté : le début spatio-temporel de la biographie du dieu chanté. Du point de vue de l'énonciation énoncée, plusieurs compositions hymniques expriment ce souci de commencer par le commencement dès le premier vers, dans la formule d'evocatio de la divinité chantée. «Je commence par chanter Déméter... et sa fille qu'Hadès a enlevée... » déclame l'aède qui s'engage dans la récitation du long Hymne bomérique consacré à la déesse d'Éleusis et à sa fille".

Le souci d'Hérodote le logographe n'est pas très différent de celui de l'aède homérique. Dans la très forte intervention énonciative qui conclut le prologue de son Enquête, le locuteur historien déclare qu'il sait qui en premier (prôton; 1, 5, 3) a donné l'impulsion (bupárxanta, de ârkhein) aux actes injustes à l'égard des Grecs; ceci en contraste avec le lógos attribué aux Perses qui font remonter à la guerre de Troie le début (arkbé; $1,5,1)$ de leur inimitié vis-à-vis des Grecs. Dans cette déclaration énonciative d'Hérodote, un simple article assorti d'une forme participiale (tôn bupárxanta, «l'initiateur») a remplacé le relatif hymnique pour introduire le sujet de l'action dont le récit va suivre. Mais, de même que dans les Hymmes bomériques et même si le repérage spatial correspondant est pour l'instant suspendu, le discours narratif est traversé par les trois lignes temporelles qu'on a indiquées: le temps de l'énonciation énoncée actualisé dans la forme du futur performatif probésomat, « je vais progresser »; le temps de la narration impliqué par la mention du " récit » et de sa progression (es tò próso tổ lógou); et finalement le temps raconté dont l'origine est donnée par le début du règne de Crésus $(1,6,1)$, l'acteur constant du récit initial de l'Enquête! Dès lors, Crésus peut apparaître - "à ce que nous, nous savons" (bemeîs ídmen; 1, 6, 2) - non seulement comme le souverain d'un royaume limitrophe des régions d'Asie habitées par les Ioniens, les Éoliens et les Doriens, mais aussi comme le premier (prốtos) des barbares à avoir soumis (katestrépsato, dans une forme de l'aoriste correspondant au temps du récit) une partie des Grecs. Le règne du roi de Lydie constitue donc l'arkhé spatio-temporelle des malheurs des Hellènes. Les trois lignes temporelles et désormais spatiales de l'Enquête d'Hérodote sont ancrées dans le même et unique point d'origine ${ }^{12}$.

\footnotetext{
11 Hymm. Cer, 1-3.

12 HDT., I, 5, 1-6, 2; sur la question de l'ärkhe en historiographie grecque, voir notamment DARBO-PESCHANSII (1995), p. 19-26. La relation que notamment Hérodote établit entre le début et la cause dans un sens à la fois moral et judiciaire en raison même de la polysémie du terme aitios
} 


\subsection{Les hommes d'or}

En relatant son avènement, le début de la description que les Travaux consacrent au génos d'or ne laisse pas la moindre ambiguité d'ordre énonciatif.

D'or fut tout d'abord la famille des hommes mortels

que créèrent les immortels qui ont leur demeure sur l'Olympe.

Ils vivaient au temps de Cronos quand il régnait dans le ciel.

Ils vivaient comme des dieux, le cour libéré de soucis...

L'usage de l'aoriste (poíesan, vers 110) situe la création de cette première " espèce» dans un passé narratif général; il est doublé d'une marque temporelle fixant cet acte au moment extrême de l'origine (prótista, vers 109). Ce moment non seulement coïncide avec le début de la narration que marque le mén introductif, avec sa valeur emphatique, fréquente dans la poésie homérique; mais il est en quelque sorte daté : il s'agit du règne de Cronos (epi Krónou, vers 111). D'emblée, et avant toute distinction par la pratique sacrificielle, la diffétence est donnée: les dieux immortels qui ont leur demeure sur l'Olympe sont distincts des hommes qui, dans leur qualification, peuvent se réclamer de Mérops, c'est-à-dire d'une figure d'ancêtre née de la terre. Dans cette mesure les hommes mortels sont l'objet d'un processus de créations successives qui se distingue du processus de la génération de type théogonique déterminant l'apparition des figures divines, même si les affinités des premiers humains avec l'or les rapproche de ces dernières ${ }^{13}$. A la logique théogonique et généalogique du egéneto, se substitue pour les hommes mortels la logique créatrice du epoíesan! Les hommes mortels ne sont pas engendrés, ils sont créés.

Néanmoins, sans y être explicitement accrochée, la succession des familles et des âges des hommes mortels s'inscrit dans la ligne généalogique qui traverse et organise le récit de la naissance des divinités dans la Théogonie. On se rappelle que si la génération de Cronos (où sont créés les hommes d'or) précède immédiatement la naissance et le règne de Zeus, cette génération est elle-même précédée des autres descendants de Ciel et de Terre. Et la naissance même de Terre remonte à Béance, posée comme entité première (prótista kháos géneto, v. 116), dans une procédure énonciative analogue à celle que l'on vient d'évoquer. En effet en demandant aux Muses, au terme d'un long proème, de lui dire "depuis le début » (ex arkhệs, vers 115) qui, parmi les immortels, est né en premier (prôton géneto, voir aussi les vers 108 et 113), le locuteur de la Théogonie engage son récit généalogique en faisant coïncider le moment de son énonciation poétique à la fois avec le début de la narration et avec le moment axial du temps raconte ${ }^{-14}$ !

\footnotetext{
a été éclairée par plusicurs études que j'ai citées ailleurs : voir CALANE (2000), p. 151-153 avec n. 14 et 16.

13 Le rapport entre méropes (ámthropoi) et le héros éponyme de cos Mérops est explicité par Chantraine (1968), p. 687. Brown (1998), p. 392-394, a montré que les objets en or sont davantage l'apanage des dieux de l'Olympe que l'attribut de la fonction royale.

'it Sur la temporalité généalogique de la Théogonie, cf. WEST (1966), p. 31-39.
} 
À cette manière de dater le début de la succession des âges créés en l'inscrivant dans la temporalité généalogique du devenir théogonique ne correspond qu'un repérage spatial implicite. Si les dieux ont leur demeure sur l'Olympe, les hommes dans leur relation avec Mérops et avec un sol bénéficiant d'une fertilité divine occupent la terre. C'est ainsi qu'après une mort ressemblant à un sommeil profond, les hommes d'or restent présents, en tant que "démons » et gardiens des mortels, sur la terre en général (epikbtónioi, vers 123). Du point de vue temporel, l'assignation de cette fonction de gardien sur terre nous transporte au règne du successeur de Cronos puisque c'est Zeus qui l'attribue aux hommes d'or effacés sous terre par Gaia, la puissance divine homonyme; mais elle nous fait aussi passer au moment de l'énonciation du poème puisque ces gardiens sont toujours présents (eisi, vers $122)^{15}$ !

\subsection{Les hommes d'argent}

La position temporelle du génos d'argent est qualifiée, dans le vers même qui l'introduit, de trois manières différentes: le deliteron initial (vers 121) introduit ce génos comme «deuxième » espèce dans un ordre de succession chiffré qui est renforcé à la fin du vers par l'adverbe metópisthen, «à la suite » et qui est évoqué au terme de ce développement, en structure annulaire, par sa reprise au vers 142 ; la succession correspond bien à une substitution puisque cette deuxième famille d'hommes est à nouveau créée (poíesan, vers 128; dans le temps du récit), à nouveau par les divinités de l'Olympe en général; enfin le comparatif kbeiróteron qui désigne ce deuxième clan l'inscrit dans un ordre de gradation morale où il apparaît comme inférieur à la famille précédente.

Ensuite, une deuxième espèce fut créée à son tour, bien inférieure, toute d'argent, par les habitants de l'Olympe,

semblable ni par sa nature, ni par son esprit à la famille d'or.

Temps de la narration et temps raconté coïncident donc à nouveau dans la présentation d'une espèce dont la temporalité interne mérite d'être relevée; une enfance particulièrement longue puisqu'elle s'étend jusqu'au terme de l'adolescence sur une durée de cent années suivie d'un âge adulte abrégé par la démesure, la violence et l'impiété qui conduit ces hommes à une rapide disparition ${ }^{16}$.

La disparition de l'espèce d'argent est l'effet de la volonté de Zeus, le « fils de Cronos » (vers 138). Cette qualification généalogique semble confirmer le fait qu'entre la naissance des hommes d'or et leur réapparition sur terre s'est implicitement opéré un changement quant à la ligne temporelle théogonique

15 Le statut des daimones, héros vivant sur ou sous terre, est bien défini par NAGY (1979), p. 152-155, ceci en rapport avec le respect de la dike par les hommes mortels. Ce statut est probablement précisé dans un fragment comique attribué à ARISTOPH., fr. 322 Kassel-Austin : cf. PARKER (1983), p. 243-245.

${ }^{16}$ Voir sur le rythme de cette biographie-type les parallèles cités par WEST (1978), p. 184-185. 
qui organise la naissance des différents dieux. Du règne de Cronos on est bien passé à celui de Zeus et la mention des autels au vers 136 présuppose peut-être l'institution du sacrifice. Quoi qu'il en soit, créés par les Olympiens et cachés par Terre comme les hommes d'or, les hommes d'argent connaissent une seconde vie non pas sur, mais sous terre (bupokhthónioi, vers 141), en contraste avec leurs prédécesseurs devenus epikhthónioi (vers 122) en tant que "gardiens» des hommes mortels. Dans cette localisation, qui concerne à nouveau toute l'étendue de la terre habitée, ces êtres « souterrains » partagent avec les dieux, qu'ils refusaient pourtant d'honorer, la qualité de «bienheureux » (mákares au vers 241, à comparer avec les vers 136 et 139 !). Sans être assimilés aux dieux, les hommes d'argent finissent néanmoins par connaître sous terre une forme d'immortalité, peut-être conformément à l'origine commune indiquée par le controversé vers 108 ! En tant que tels, ils jouissent tout de même de certains des honneurs qu'eux-mêmes refusaient aux dieux de l'Olympe. Dans cette mesure, ils bénéficient d'un statut qui n'est pas sans rappeler celui que l'Odyssée accorcle par exemple aux Dioscures: les héros jumeaux sont recouverts par la terre nourricière avant de recevoir de la part de Zeus l'honneur d'une existence alternant sous terre entre vie et mort $^{17}$.

Du point de vue énonciatif, la narration de la mort des hommes d'or et de leur installation sous terre en tant que "bienheureux " est marquée par un passage temporel de l'aoriste aux formes du présent. Au terme du récit concernant le second génos de mortels, le temps raconté et le temps de la narration viennent à nouveau cö̈ncider avec le temps de l'énonciation énoncée. En effet, cette deuxième famille d'êtres humains (deiterol, au vers 142 , en écho annulaire avec le vers 127 , comme on l'a signalé), avec sa dénomination particulière, est encore honorée dans le présent de la récitation du poème. On ajoutera que dans cette même perspective de coïncidence avec le temps de l'énoncé de l'énonciation, la qualification de l'homme d'argent au moment de sa longue enfance comme mégas népios (" gros enfant », vers 131) n'est pas sans évoquer l'adresse à Persès en tant que tel au terme de la section du poème portant sur le respect de la justice (vers 286$)^{18}$ !

\subsection{Les hommes de bronze}

Zeus est désormais le maître d'œuvre unique de la succession des familles d'hommes mortels. C'est donc à lui qu'il incombe de fabriquer le clan des hommes de bronze, le troisième - indique le texte dans une formulation très proche de celle décrivant la naissance du premier.

17 Cf. HOM., Od. XI, 301-304, avec le commentaire de WEST (1978), p. 186-187. Le paradoxe de la timé accordée par Zeus aux hommes d'argent alors qu'eux-mêmes n'en offraient aucune aux dieux de l'Olympe est marqué aussi bien par la structure en chiasme des vers 138-142 que par l'expression laci tôtsin au vers 142 .

${ }^{18}$ Cf. SCHMIDT (1986), p. 31-40 et $49-52$. 
Zeus le père créa une troisième espèce d'hommes mortels de bronze, en rien semblable à celle d'argent, à partir des frênes, d'une force terrible.

Génos de bronze créée à partir des frênes donc, dans une probable allusion à une légende pour nous beaucoup plus tardive qui fait naître le genre humain de ces arbres, de même que d'autres versions de la naissance des hommes font surgir les premiers mortels du chêne. Au-delà de ce que propose le texte des Travaux; on peut à nouveau tenter de rapprocher la chronologie dessinée par le récit des âges avec la ligne narrative qui organise le temps raconté dans le récit généalogique de la Théogonie. On constatera alors que, dans le résumé préalable du processus théogonique que le poète place dans la bouche des Muses, le genre humain apparâ̂t à la suite de la naissance de Zeus, en même temps que "la génération des puissants Géants ». Par ailleurs, dans le récit théogonique lui-même, les Nymphes des frênes naissent au moment même où les Géants surgissent tout armés de Terre, fécondée par les éclaboussures du sang jailli des parties génitales d'Ouranos, lui-même castré par son fils Cronos ${ }^{19}$. Par l'intermédiaire des Nymphes, les hommes de bronze des Travaux seraient aussi nés de la terre, mais en un temps qui se situerait bien après le terme du règne de Cronos et à la suite de l'avènement de Zeus, implicitement né - on l'a vı - à l'issue du temps des hommes d'or!

Même s'il est dit «en rien semblable à la famille d'argent" (vers 144), le génos de bronze partage avec les hommes précédents des traits assez nombreux pour s'inscrire dans leur suite non seulement du point de vue temporel, mais également du point de vue sémantique. Comme les hommes d'argent, les hommes tout de bronze vêtus font preuve d'une folie et d'une démesure qui les engagent à retourner leur violence contre eux-mêmes. Mais la force brute de ces hommes, s'exerçant en particulier dans le domaine de la guerre, est telle que finalement Zeus n'a pas besoin d'intervenir pour consommer leur disparition définitive ${ }^{20}$. Par ailleurs à l'impiété se substitue dans la caractérisation hésiodique de la famille de bronze l'absence d'alimentation fondée sur les travaux agricoles. Ainsi, et de manière entièrement négative, le profil des hommes de bronze s'inscrit dans deux des grandes isotopies qui traversent le poème pour assurer sa cohérence sémantique : administration de la justice et production du bios. On pourra rappeler ici que la démesure violente opposée à l'équilibre de la justice, la piété envers les dieux et la consommation du pain constituent quelques-uns des critères de

19 HÉs., Th., 41-51 et 183-187; cf. schol. ad Th, 187 (p. 40 Di Gregorio). Pour les nymphes des arbres, voir références données par WEST (1978), p. 187; selon NAGY (1979), p. 158-159, le bois de frêne serait à référer à la hampe de la lance des héros homériques avec sa pointe de bronze.

20 On remarquera que, réapparaissant et dans $T b$., 151-152 et dans $S c$., 75-76, les vers 148 149 ne sont pas nécessaires à l'économie sémantique du passage; il s'agit peut-être d'une interpolation : cf. WEST (1978), p. 188, et, de manière générale, CARRièRE (1986), p. 200-203. 
l'aune à laquelle sont mesurés les êtres plus ou moins sauvages rencontrés par Ulysse et ses compagnons au cours du voyage de retour vers Ithaque ${ }^{21}$.

À cause de la violence guerrière qu'ils exercent dans des luttes intestines, les hommes de bronze disparaissent donc d'eux-mêmes. Sans doute est-ce la raison pour laquelle il ne reste pas d'eux la moindre trace qui serait attachée à un nom, et par conséquent à une renommée : ils sont nónunol, "sans nom " (vers 154); mais, dans un probable jeu de mot étymologisant, ils sont aussi privés du chant d'éloge (búmnos) qui en perpétuerait la mémoire ${ }^{22}$. Ils ne connaissent donc aucune forme d'immortalisation et ils n'ont qu'une existence éphémère sous le soleil. Dans cette mesure, on ne saurait leur attribuer une quelconque fonction dépendant de l'idéologie indo-européenne à l'intérieur de l'hypothétique structure synchronique qui sous-tendrait la temporalité de la succession des cinq âges! En concomitance avec cette absence d'identité héroïsante désignée par un ónoma et en concordance (négative) avec l'isotopie de la parole proférée et efficace qui traverse le poème en tant que troisième ligne de cohérence sémantique, le temps et l'espace des hommes de bronze ne peuvent pas être référés au bic et nunc de l'énonciation, comme c'était pourtant le cas pour les générations précédentes. En revanche, la brève allusion à l'inexistence du fer' met la famille de bronze dans la perspective du cinquième génos et par conséquent de la cinquième période : celle à laquelle le locuteur indique - comme on le verra - qu'il appartient lui-même. Par ce biais, la cohésion chronologique du récit dans la coïncidence de la temporalité de la narration avec le temps raconté et dans la correspondance avec le temps de l'énonciation énoncée est en substance, et malgré tout, sauvegardée.

\subsection{L'âge des héros}

L'introduction du génos des héros est régulièrement apparue comme une irrégularité puisqu'elle rompt avec la logique de la succession des métaux apparemment organisée selon l'échelle des valeurs qui leur sont culturellement et respectivement attribuées. Néanmoins du point du vue de la temporalité narrative et discursive, cette nouvelle famille s'inscrit parfaitement dans la séquence dessinée par les trois familles précédentes. Toutes les marques temporelles qui organisent la syntaxe de ces vers d'introduction concourent à établir cette continuité.

Puis quand la terre eut également fait disparaitre ce clan,

à nouveau Zeus le fils de Cronos en créa encore un autre,

le quatrième sur le sol nourricier, plus juste et plus valeureux,

espèce divine des hommes héros, qu'on dénomme demi-dieux,

génération précédente sur la terre sans limites.

${ }^{21}$ Comme c'est par exemple le cas des Cyclopes de l'Odyssée : cf. Hom., Od. IX, 105-115 et $172-176$.

${ }^{22}$ Pour nōnymmos dans le sens de "sans gloire", voir HOM., Il. II, 70; XIII, 227 ou XTV, 70, en contraste avec l'espoir des hérönes et des héros de devenir aoídimoi, objet du chant des aèdes, telle Hélène dans $I l$. VI, 358; $c f$. CARRIÈre (1986), p. 203. 
En plus de l'usage régulier de l'aoriste qui prolonge la référence au temps passé du récit, l'ordre de succession de la famille des héros par rapport au génos de bronze est souligné par une subordonnée temporelle. Cet énoncé rappelle la disparition sous terre des hommes de bronze, tandis qu'un kat signifiant "également» (vers 156) souligne la relation avec les deux familles précédentes, dans une reprise du vers 140 . Si la place du clan des héros dans la succession des géne est indiquée par son numéro d'ordre (tétarton, " quatrième »), sa création par Zeus est inscrite dans un mouvement de réitération signifié autant par l'usage de an̂tis, «à nouveau », que par l'emploi de éti, «encore ». De plus, ce génos des hommes héroïques est inséré dans la hiérarchie des valeurs qui ordonne chronologiquement les familles précédentes tout en les caractérisant. Il est en effet jugé à l'aune de la justice et de l'isotopie qui traverse toute la première partie du poème. De ce point de vue, cette famille se révèle "meilleure ", ceci peut-être en concomitance avec sa qualité héroïque qui rompt avec la dégradation attachée à la représentation de la succession des métaux ${ }^{23}$. Enfin, du point de vue spatial, sa localisation sur la terre « sans limites » (v. 160) est mise pour la première fois en relation avec la productivité et le rôle alimentaire de ce sol.

Quelle qu'en soit la qualité comparative, ce génos n'est plus simplement formé d'êtres humains (ánthropoi), mais d'hommes de sexe masculin (ándres, vers 159), d'hommes qui partagent néanmoins avec les dieux une part de leur divinité originaire (thềon, peut-être par référence au vers 108 !). Dans cette mesure, et contrairement aux famille précédentes, le génos des héros reçoit d'emblée la qualification qui est la leur clans le présent de l'énonciation : non pas des gardiens epikbthónioi, non pas des bienheureux bupokbthónioi, non pas des "sans nom », mais des bemitheol (vers 160), moins des « demi-dieux " que des hommes à moitié divins par leur ascendance; tels sont par exemple les Argonautes chez Pindare, les compagnons «au bouclier de bronze » de Proïtos chez Bacchylide, ou les Hippocoontides de Sparte chez Alcman ${ }^{24}$. Quand le Catalogue des femmes attribué à Hésiode mentionne la volonté de Zeus de détruire les hommes en provoquant la guerre de Troie, il les englobe dans la "famille des hommes mortels » (génos merópon änthropon, vers 98); ces mortels sont des «demi-dieux» parce qu'ils sont les enfants des dieux bienheureux qui conduisent à l'égard de ces «hommes héros » une vie séparée ${ }^{25}$.

La qualification de «semi-divin » est référée au temps de l'énonciation par le présent kaléontai (" on les appelle», vers 159; cf. vers 141). Cette référence

${ }^{23}$ L'impact de l'insertion du clan des héros dans la succession des familles désignés par un métal est relevé et commenté notamment par CARLIÈre (1996), p. 411-413, et par Couloubarirsis (1996), p. 492-500 (même si l'ordre de succession des familles ne relève en rien de la généalogie !).

${ }^{24}$ Cf. PIND., Pyth. 4, 12 et 211; BaCchrl., 11, 62; AlCM., fr. 1, 7 Page-Davies; utiles références complémentaires chez WEST (1978), p. 191.

${ }^{25}$ HFs., fr. 204, 95-119 Merkelbach-West. Pour les sens homérique de bérós en tant que "jeune guerrier" appartenant au passé épique, mais sans allusion à un culte héroïque, $c f$. WEST (1978), p. 370-373. 
est transformée en une véritable focalisation à partir de ce moment présent par l'usage de l'adjectif protére (vers 160) : le génos des héros représente la quatrième espèce par rapport au point axial du temps raconté, mais la " précédente » dans la perspective de la temporalité de l'énonciation énoncée. De plus, cette espèce humaine n'est plus uniquement un génos parmi d'autres, mais une geneé, c'est-à-dire qu'il constitue (enfin !) une véritable " génération ». Il s'agit donc de la génération des héros qui précède immédiatement la génération à laquelle appartient le locuteur-narrateur, une génération dont la localisation couvre elle aussi la terre entière ${ }^{26}$.

De même que pour l'espèce de bronze, ce n'est pas Zeus qui consomme la disparition de la génération des héros, mais l'activité à laquelle se livrent ces derniers : non plus la stásis, mais le pólemos, non plus la violence mutuelle dans les luttes intestines constamment condamnée en Grèce classique, mais la guerre extérieure portée en deux lieux particuliers - Thèbes aux sept portes en terre cadméenne, Troie atteinte par bateau par-dessus l'abîme marin. À ces deux localisations soudainement précises s'ajoutent deux noms propres, en contraste avec le destin anonyme connu par les hommes de bronze. Présentés comme causes respectives de l'une et de l'autre de ces deux expéditions guerrières, CEdipe et Hélène apparaissent en quelque sorte comme les synecdoques de ces deux entreprises épiques, narrées dans les deux grands cycles de la poésie homérique ${ }^{27}$.

Dans la tradition papyrologique déjà, la structure syntaxique de l'ensemble de ce passage a fait l'objet de manipulations et d'interpolations nombreuses. Néanmoins, dès lors que l'on se rappelle que dans l'Odyssée elle-même les participants à la guerre de Troie, en raison même de leur démesure, connaissent après la mort des destinées différenciées par la mort, les difficultés de lecture s'aplanissent. L'ensemble des hommes de l'espèce des héros se livre donc à la guerre (loùs mén, au vers 161 comme aux vers 122, 137 et 141), pour se diviser en deux catégories selon qu'ils se sont battus autour de Thèbes (toùs mén, vers 162) ou sous les murs de Troie (toùs dé, vers 164). Ce mouvement à la fois temporel et spatial est repris par l'adverbe éntha (« en cet endroit-là » et "à ce moment-là ») introduisant le vers 166 dont certains lecteurs ont pensé pouvoir faire l'économie dans l'Antiquité déjà. Marqué par une modalisation énonciative forte ( $\underline{\hat{e}}$ to $i$, "en vérité »), ce vers clôt en structure annulaire l'allusion à la disparition par fait de guerre des héros en général tout en introduisant une nouvelle distinction : les uns (toùs mén, vers 166) furent enveloppés non pas par la terre, mais par la mort dans son accomplissement (de même que les hommes de bronze !); les autres (tô̂s dé, vers 167) furent établis par Zeus aux confins de la terre où ils connaissent (désormais) un mode de vie privilégié. C'est dire que les uns disparurent dans l'Hadès, tels Achille, Agamemnon ou Ajax rencontrés par Ulysse à l'occasion

26 Le sens généalogique de geneé est relevé en particulier par Crubeller (1996), p. 439 n. 27 , et par MosT (1997), p. 111-114.

27 Pour les deux grands cycles épiques, voir WEST (1978), p. 191-192, et NAGY (1979), p. $161-166$. 
de la descente aux enfers que raconte l'Odyssée, alors que d'autres sont assignés aux îles des bienheureux à l'instar de l'avenir promis à Ménélas dans le même poème homérique. De même qu'au vers 161 toùs mén assorti du connecteur kaí reprend la catégorie des héros semi-divins qui vient d'être présentée, de même au vers 170 , la combinaison identique de toì mén avec kaí reprend la sous-catégorie des héros privilégiés qui vient d'être délimitée pour décrire l'espace particulièrement fertile qui leur est réservé jusque dans le présent de l'énonciation ${ }^{28}$.

Comme pour les groupes humains précédents, la description du (double) destin réservé à la famille des héros demi-dieux débouche donc sinon sur le bic, en tout cas sur le nunc de l'énonciation énoncée. Après leur installation par Zeus aux confins de la terre habitée, les héros privilégiés demeurent maintenant (naíousin, vers 170) auprès du fleuve Océan qui délimite les terres les plus éloignées; c'est là que se situent des îles des bienheureux que l'on n'a aucune peine à identifier avec le Champ Élyséen annoncé à Ménélas dans l'Odyssée. On aura l'occasion de revenir longuement au chapitre $V$, à propos des lamelles d'or sur cette conception d'un au-delà partagé entre l'obscurité humide de l'Hadès et la lumière hérö̈sante baignant des prairies verdissant dans un printemps éternel ${ }^{29}$. Ce retour du temps de la narration et clu temps raconté au temps de l'énonciation est souligné par la forme qu'assume la qualification de ces hommes en tant que «héros bienheureux» (ólbioi béroes, vers 172) : la forme de l'apposition évoque la forme particulière de l'adresse générale dénommée makarismós; par la formulation "bienheureux ceux qui... ", il s'agit précisément de vanter le bonheur des mortels qui, dans leur trépas, ont atteint une forme d'immortalité les rapprochant des dieux ${ }^{30}$.

Retour à l'âge d'or dans une conception cyclique du temps qui référerait le destin connu par les héros bienheureux au mode de vie dont jouissaient les hommes d'or? Pas tout à fait dans la mesure où, si l'évocation des îles des bienheureux permet en effet un retour à l'isotopie du bien-être résultant de l'abondance agricole, il y a tout de même entre âge d'or et âge des héros un double glissement ${ }^{31}$. Glissement temporel d'abord puisque l'abondance de la

28 Iá construction de ce passage difficile, dans la combinaison des mén et des dé, est explicitée par CARRIÈre (1991), p. 97-99. Pour le destin particulier d'Achille, partagé selon les versions de la légende héröque entre l'Hadès et les Champs Élysées, voir NAGY (1979), p. 165173.

29) HOM., Od. IV, 561-569, avec le commentaire donné en particulier par SoURVINOU-INWOOD (1995), p. 17-92; voir aussi BROWN (1998), p. 397-401.

3i1 Le plus bel exemple de makarismós est offert par la conclusion de l'Hymm. Cer., 480-489, qui par deux fois promet aux mortels se prêtant aux ôrgia initiatiques proposés par Déméter à Éleusis une vie meilleure après la mort; voir aussi PIND., fr. 137 Maehler, accompagnée du contesté fir 133 Maehler qui fait des mottels privilégiés par Perséphone des êtres qui "pour le reste du temps sont appelés (kaléontai) héros purs (bérọes hagnoî) par les hommes».

31 Un retour à l'âge d'or qui ordonnerait les quatre premières "générations » en une représentation cyclique correspond à l'hypothèse formulée en particulier par NAGr (1979), p. 169-171; voir aussi, dans une image intégrant une ligne d'ordre généalogique, Couloubarrrsis (1996), 
production d'un sol particulièrement fertile se réfère au passé de la vie des hommes d'or alors qu'elle marque le présent de la destinée post mortem des héros vivant sur les îles des bienheureux; glissement sémantique ensuite dans la mesure où, au-delà de la structure annulaire qui semble référer les vers 172-173 aux vers 117-118 (notamment par la réitération de l'expression formulaire zeidoros äroura), une floraison trois fois l'an est venue se substituer à la production spontanée de l'âge d'or. Si cette dernière est traditionnellement attribuée au règne utopique de Cronos, la première est typique de terres particulièrement fertiles, mais cultivées par des mortels, tel le territoire de Cyrène en Libye! Cette différence dans l'absence de retour cyclique n'a pas échappé à Platon lui-même qui, dans le commentaire étymologisant qu'il offre du récit hésiodique dans le Cratyle, ne manque pas de référer la famille des héros aux hommes d'or; mais si ceux-ci sont des êtres sensés dans la mesure où daímones doit être rapproché de daémones, "savants ", ceux-là dont des béroes parce que, par l'intermédiaire de eirein, "dire», ils sont d'habiles rhéteurs... ${ }^{32}$.

\subsection{Les hommes de fer}

On aura désormais reconnu que s'il y a un récit qui doit être soustrait au principe structural de l'immanence textuelle, c'est bien le «mythe des races». La position structurale assumée par la cinquième espèce, celle des hommes de fer, est en effet incompréhensible si on ignore qu'elle est d'emblée située dans la perspective du locuteur-narrateur et par conséquent de celui qui chante le poème des Travaux. Ce déplacement d'un mode narratif à une tournure énonciative, ce passage de l'ordre du « récit » à celui du «discours » est si marqué que l'intervention du je se substitue à la description, attendue, de la création de cette espèce de fer.

Puissé-je quant à moi ne pas vivre à mon tour parmi les humains cinquièmes, mais ou bien être mort avant ou bien être né après.

En effet c'est maintenant précisément l'espèce de fer. Ils ne cesseront de subir fatigues et misères, jamais, ni de jour, ni de nuit.

Les dieux leur enverront de pénibles préoccupations.

En exprimant le souhait d'être exclu d'un «maintenant » coïncidant simplement avec l'existence des hommes (ándres, vers 175) appartenant au génos de fer, le locuteur impose sa propre temporalité énonciative à celle de la narration et au temps raconté. Le point axial de ce temps présent, en contraste avec le prótista du vers 109, est signifié par le connecteur nûn gàr dé,

p. 492-500 et 517. La prise en compte du vers 169 qui attribue à Cronos le règne sur les îles des bienheureux semble confirmer l'enfermement du temps dans un cercle; mais ce vers 169 réapparaît comme premier vers d'une séquence explicative (vers 173a-e) probablement interpolée et présente uniquement dans deux papyrus : cf. WEST (1978), p. 194-196, et CARrière (1991), p. 86-97.

32 Plat., Crat., 397e-398d. Pour la fertilité du sol de Cyrène, cf. CaLAME (1996a), p. 145-147. 
«car maintenant précisément», situé en position forte au vers $176^{33}$. C'est dire qu'il coïncide désormais avec le point axial du temps de l'énoncé de l'énonciation, un point qui coïncide lui-même avec l'espace ponctuel non nommé d'où parle le locuteur. Cette correspondance institue une tension forte avec le prótista qui marquait, au début de la narration, le point axial du temps raconté, coïncidant sur le plan sémantique avec la création de l'espèce d'or.

À moins d'admettre l'insertion des vers $173 \mathrm{a}-\mathrm{e}$ qui, offerts de manière fragmentaire par deux papyrus, ont une fonction à la fois explicative et normalisante quant au passage du quatrième au cinquième génos, les hommes (andrásin, vers 175) de l'âge de fer ne sont donc pas l'objet d'un acte de création par Zeus. Du point de vue temporel et spatial, leur existence est essentiellement repérée par rapport au bic et munc de l'énonciation, c'est-àdire par rapport au je (egó, ver's 173) du locuteur-narrateur. Cette situation énonciative n'est pas sans rappeler celle qui conclut le prélude du poème : le je du poète s'y substitue à Zeus pour se situer de manière décidée face à Persès (à la troisième personne !). Tout se passe comme si la famille de fer était, maintenant, du ressort de celui qui assume l'instance d'énonciation! C'est ce qu'intuitivement semble bien comprendre le Socrate mis en scène par Platon dans le Cratyle quand il associe ses contemporains, dans un nous inclusif, à l'espèce de fer telle qu'elle est décrite précisément par Hésiode, en contraste avec le génos d'or ${ }^{34}$.

Désormais mort (thanên, vers 175) et naissance (genésthai), dans l'ordre inversé, ne sont plus celles d'une espèce humaine, mais celles du je. Cette nouvelle temporalité de l'énonciation énoncée est ainsi constituée d'un «avant » (prósthe, vers 175), qui pourrait situer la disparition souhaitée par le locuteur dans la période des héros (en correspondance peut-être avec le protére du vers 160), et un "après " (épeita) qui suit implicitement la période des hommes cle fer.

En effet si l'acte de création de l'espèce de fer n'est pas mentionné, sa destinée est longuement décrite. Dans un premier moment, le destin de cette famille composée d'hommes formulairement attachés à la terre (génos merópon anthróponn, vers 180) de même que les espèces d'or et de bronze (vers 109 et vers 143) est présenté comme une séquence ininterrompue de peines et de soucis envoyés nuit et jour par les dieux. Les biens ne parvenant pas à compenser les maux, cette espèce finira elle aussi par connaitre une perte consommée par Zeus (Zeüs d'olései kai toûto génos, vers 180; dans une forme verbale désormais au futur). À partir de cette première incursion dans le futur de l'espèce de fer pour en envisager la ruine, le mouvement temporel imprimé à la narration est loin d'être indifférent. Le moment futur de la destruction de cette espèce par la volonté du fils de Cronos est immédiate-

33 VERNANT (1960), p. 26, interprète le regret d'Hésiode de ne pas être mort ou "avant " ou "après" (la race de fer) comme lindice que la séquence des âges représente un "cycle renouvelable ». Contra LECLERC (1993), p. 220.

3f PLAT., Crat., 398a. Pour la structure de ces vers 9-10 du prélude des Tiavaux, voir CALAME (1996b), p. 170-175. Quant au statut des vers 173d-e, cf. supra n. 31. 
ment précédé d'une phase de brouillage complet des relations sociales de confiance réciproque dans la famille, dans la communauté politique et avec les dieux : manière de renouer par la négative avec l'isotopie de l'administration de la justice, voire avec celle de l'abondance agricole dans le refus de nourrir ses parents, mais aussi avec celle de la parole droite qui est mise en place dans le prélude. Non seulement les hommes de fer finiront par confier l'équilibre de la justice à la violence physique (dike d'en khersí, vers 192) en se comportant dès lors comme les hommes de bronze, mais surtout ils se livreront au reproche médisant (mémpsontai, vers 186) et, par des discours courbes (mithoisin skolioîs, vers 194), ils assureront le triomphe du mauvais sur le meilleur (areiona, vers 193; qualification de l'espèce des héros au vers 158).

Cette situation d'entière confusion sociale est marquée par une série d'états pratiquement tous introduits de manière négative par la conjonction oudé. Du point de vue du temps et du rythme de la narration, cette séquence est conduite au point de non-retour signifié par tóte, «à ce moment-là », au vers 197 (souligné par le connecteur kai dé). L'annonce de la destruction par Zeus des hommes de fer au début de la description qui leur est consacrée fait attendre sa répétition ici, en position d'écho annulaire. En réalité, le repère temporel tóte renvoie à une étape précédant cette destruction; il se réfère au moment où, n'y tenant plus, Aidôs et Némésis quitteront les hommes et la terre pour rejoindre les immortels sur l'Olympe.

Puis le Zèle suivia les hommes de vie miséreuse,

le médisant, au front dégoûtant, qu'égaient les misères.

Et, quittant pour l'Olympe la terre aux larges routes,

revêtant leur corps magnifique de voiles splendides,

abandonnant les mortels - s'enfuiront vers la troupe immortelle

Némésis et Pudeur : il ne restera plus chez les hommes

que les lugubres douleurs. Le mal n'aura plus de remède.

(trad. Philippe Brunet)

En consommant ainsi la séparation entre les humains et les dieux, Pudeur et Indignation, toutes deux des puissances assurant respect et renommée par la parole, laisseront les hommes mortels seuls avec leurs maux, sans moyen pour s'en défendre ${ }^{35}$. La disparition de l'espèce de fer et sa destruction par Zeus restent de simples conséquences implicites du comportement de ces hommes de fer.

C'est dire que, contrairement aux narrations déroulant le destin imposé à chacune des quatre espèces humaines précédentes, le récit ne connaît pas ici de conclusion narrative, ni positive ni négative. La structure qui porte sa logique ne connaît pas de réalisation complète. Cet inachèvement s'explique naturellement par la tournure prophétique, souvent reconnue en tant que telle, qu'assume la narration pour l'espèce de $\mathrm{fer}^{36}$ : la destinée promise aux

\footnotetext{
${ }^{35}$ Le sens de aidós dans ce contexte est explicité notamment par SCHNIDT (1986), p. 60-66.

36 Voir par exemple West (1978), p. 176 et 198, et CARRIÈre (1996), p. 424-427.
} 
hommes vivant dans le présent du locuteur-narrateur n'est qu'une possibilité, soulignée par l'emploi de l'optatif aux vers 187-188. Du point du vue de sa logique narrative, le lógos des géne reste donc ouvert. En correspondance avec la projection dans un futur probable du temps raconté et du temps de la nartation à partir du point axial du temps de l'énonciation énoncée, ce récit ne connaît d'achèvement ni du point de vue logique, ni du point de vue sémantique. En termes sémio-narratifs, cela signifie qu'il ne débouche pas sur une phase de «sanction». Certes, le locuteur-narrateur envisage, au sein de ce règne absolu du mal qui s'étend implicitement à l'ensemble de la terre habitée (cf. vers 197), la séparation complète et définitive entre les hommes mortels (thnetoi ánthropoi, vers 201) et la tribu des immortels (athanáton phîlon, vers 199); mais la destruction de l'espèce de fer par Zeus n'est pas reprise, annulant ainsi l'effet de Ringkomposition attendu!

La narration du lógos inscrit donc les cinq géne dans une même séquence temporelle et logique qui conduit l'auditeur, puis le lecteur du point axial premier initiant le temps raconté (prọtista, vers 109) au futur possible (éssetai, vers 201) envisagé à partir du point axial du temps de l'énonciation (ópbellon egó, vers 174; nîn gàr dé... esti, vers 176); ce temps correspond aussi au temps de l'acte de parole performatif qui signale le début de la narration (ekkoruphóso, vers 106). La suspension temporelle et logique du récit restitue donc au locuteur, et par conséquent au poète, le pouvoir d'achever le récit à sa guise. Il en va de même des deux récits qui encadrent le lógos des cinq familles humaines. Sa temporalité ne peut être comprise que dans ce contexte narratif.

\section{Contexte narratif et poétique}

De même que le lógos des cinq familles d'hommes lui-même, ni le récit de Pandôra qui le précède, ni la fable du rossignol et de l'épervier qui lui fait suite ne se referment sur eux-mêmes dans une véritable phrase de sanction narrative.

\subsection{Le récit de la jarre d'Espoir et la fable du rossignol-aède}

J'ai tenté de montrer ailleurs que l'achèvement logique de la version particulière du récit de la création de Pandôra offerte dans les Travaux n'est qu'apparent $^{37}$. À la double colère de Zeus d'une part figurée allusivement par le retrait du bíos spontané et d'autre part provoquée par le vol du feu par la ruse de Prométhée au profit des hommes pourrait correspondre la double sanction offerte dans ce premier récit : fabrication de Pandôra et don aux hommes «qui se nourrissent de pain» de ce malheur (pệma, vers 82) trompeur; par la présence de la femme, diffusion auprès des hommes, sur terre et sur mer, de maux, de maladies et de sinistres chagrins (kédea lugrâ,

37 CALAME (1996b), p. 181-189. Pour la question de l'« allocuté », et donc du destinataire des Travaux, cf. supra n. 5. 
vers 95). Du point de vue spatial, le partage est achevé entre les dieux qui «tous» (pántes, vers 81) habitent l'Olympe, et qui à ce titre participent à l'étymologie du nom de Pandôra ("le don de tous»), et les tribus des hommes qui vivent sur la terre (epi khthóni, vers 90) qu'ils cultivent. Néanmoins la présence d'Elpis au fond de la jarre d'où sont sorties ces tristes afflictions indique que l'état narratif atteint à la suite de la création de Pandôra et après l'ouverture de la jarre est loin d'être stable; et ceci d'autant moins que la fermeture du pithos avant qu'Espoir à son tour ne s'en échappe a été voulue par Zeus lui-même.

Thématisée dans la séquence des dons et contre-dons trompeurs de Zeus aux hommes dans une véritable leçon de réciprocité et de rétablissement de l'équilibre juridique, l'isotopie de la justice se combine avec celle du travail productif pour donner au récit de Pandôra à la fois son épaisseur sémantique et sa fonction étiologique quant à la condition de mortel. Son mouvement narratif et temporel en tension entre un point d'origine marqué par la convivialité avec les dieux et le présent de l'énonciation avec sa situation de déséquilibre débouche sur un état précaire qui requiert, comme dans le récit des cinq âges, un complément, sinon une « sanction » sémio-narrative.

La nécessité de ce complément narratif s'impose également à l'issue de l'autre récit encadrant le lógos des cinq espèces d'hommes. Il s'agit de la célèbre fable (ainos, vers 201) de l'épervier et du rossignol, adressée plus spécifiquement au troisième des allocutaires alternés des Travaux: après Persès, après le $t u$ générique, les « rois ». L'apologue est raconté à l'aoriste; ce temps renvoie à un passée si indéterminé qu'il peut dans le cas particulier avoir une valeur gnomique. Mais la narration de l'aînos animal est surtout référée au temps de l'énonciation. Par la forme eréo (vers 202) elle est branchée sur le même nûn, le même moment présent que celui qu'allègue le locuteur pour tenter de se soustraire à la période de fer (vers 176); elle est saisie en tant qu'acte de parole par la même forme du futur performatif que celle engageant l'ensemble du récit des âges (vers 106). Il s'agit ici simplement de "dire " la fable de même que le locuteur introduit la seconde grande partie du poème, consacrée aux Travaux, en manifestant sa volonté de dire ces vers (eréó, vers 286) à Persès; de même aussi qu'au seuil de l'ultime section de la composition, le locuteur annonce son intention, en racontant les saisons de la navigation et les jours favorables, de dire (eréo, vers 661) le dessein de Zeus.

Avec sa référence à un passé « aoristique » au sens étymologique du terme et par l'insertion en discours direct et par conséquent au présent des mots que l'épervier (ou le faucon?) adresse au rossignol prisonnier de ses serres, la narration de la fable provoque une sorte d'aplatissement de la profondeur temporelle manifestée dans les deux récits précédents : le passé gnomique du temps raconté semble coïncider sans intermédiaire, et sans point axial d'origine autre que le début de cette brève narration, avec le temps de l'énonciation. Par ailleurs, en tant qu'ainos, la fable est de manière étymologique et constitutive une invitation à déchiffrer une conduite narrative «énigma- 
tique ${ }^{34}$. Autant les valeurs mélodiques et poétiques traditionnellement attribuées au chant du rossignol que le jeu de mots explicite du texte qui associe l'aedôn (vers 203) à l'aoidós (vers 208) conduisent à identifier la plainte mélodieuse du rossignol avec celle du locuteur, poète et aède. Dans ces conditions, loin de représenter abstraitement un présage destiné à Persès ou une incarnation de la vengeance des dieux comme cela a été proposé récemment, l'épervier correspond au destinataire du locuteur et de la fable, c'est-à-dire les rois; du moins provisoirement ${ }^{39}$.

En effet, ni dans la logique narrative, ni dans sa morale, la fable ne comporte de phase de «sanction ». Conséquence de la buibris illustrée par le pouvoir violent de l'épervie1-roi, le déséquilibre narratif provoqué par l'injustice initiale ne connaît pas de rétablissement. Dans son gémissement plaintif, évoquant le chant de chouette des jeunes filles encore immatures prononçant l'un des Paithénées d'Alcman ${ }^{40}$, le rossignol-aède ne donne aucune réplique articulée aux paroles brutales de l'oiseau de proie. En s'attribuant le pouvoir discret soit de manger, soit de relâcher le pauvre rossignol, l'épervier s'arroge le futur prophétique; il est le seul à donner une morale qu'il tire de sa propre formulation de la loi du plus fort : pour qui tente de répliquer, les douleurs s'ajoutent aux infamies (aískbesin álgea vers 211). Discret, l'écho est néanmoins évident avec le terme de l'âge de fer qui voit le départ de Pudeur et d'Indignation, livrant les mortels aux «tristes douleurs » (álgea lugrä, vers $200)^{41}$.

Ni le récit de la fabrication de Pandôra, ni la séquence cles cinq âges, ni même la fable de l'épervier et du rossignol ne trouvent donc la sanction narrative et éthique attendue. En revanche, tout se passe comme si le récit de Pandồa illustrait l'isotopie du travail productif, le lógos des cinq espèces celle de l'équilibre de la justice, et la fable ornithologique celle de la parole poétique argumentée et efficace !

\subsection{Efficacité poétique entre justice et ressources de vie}

Le rétablissement de l'équilibre narratif des trois lógoi enchaînés est en définitive le fait du poème lui-même, du poème assumé par la voix du locuteur-aède. En effet, à la réplique attendue de la part du rossignol-aède se substitue la nouvelle invite impérative assumée par le locuteur-narrateur et adressée à Persès. Par sa formulation ( $̂$ ô Persès, quant à toi écoute la justice et ne nourris pas la démesure "; ô Pérse, sù d'ákoue dikeses, méd'búbrin óphelle,

38 Le statut narratif et pragmatique de l'aînos a été bien défini par NAGY (1990b), p. 147-150 et 309-313.

3) Aucune des interprétations de la fable proposées dans les études que j'ai citées (voir CALAME [1996)] 188 n. 50), n'est à cet égard satisfaisante; voir aussi les indications bibliographiques données par WEST (1978), p. 204-205.

f1 Cf. ALCM., fr. 1, 85-87 Page-Davies, avec les parallèles complémentaires mentionnés par WEST (1978), p. 207.

${ }^{41}$ Douleurs qui rappellent les kéclea lıgrá qui sont la conséquence de l'ouverture de la jarre dans le récit de Pandôra : cf. vers 49 et 95 , ainsi que supra $\$ 4.1$. 
vers 213), cette adresse reprend la double invitation (positive et négative) marquant le début du poème ( ô Persès, quant à toi fixe fermement ces avis en ton esprit "; ô Pérse, sù dè tấta teôi enikátheo thumối, vers 27). Tout en encadrant l'ensemble des trois récits, la nouvelle adresse d'une part associe Persès aux rois en tant que figure sous-jacente au masque "énigmatique " de l'épervier de la fable; d'autre part, elle assume la forme d'une recommandation quant au respect de la dike et du refus de l'búbris (vers 213). Ce faisant, elle reporte précisément des trois récits au poème lui-même la sanction narrative et morale attendue. Ce sont donc les recommandations adressées à Persès dès le vers 213, puis aux rois dès le vers 248 qui achèvent la logique à la fois discursive et éthique des récits enchaînés.

Ce rétablissement, ce rééquilibrage, désormais d'ordre discursif et énonciatif, s'opère aussi bien sur le plan sémantique que dans la dimension temporelle. Du point de vue sémantique, les recommandations faites à Persès sur le mode assertif de la sentence renouent avec les isotopies du droit et de la fécondité productive posées dans le proème et dans la partie introductive du poème. Pour faire bref et ne pas répéter ce que j'ai déjà indiqué ailleurs sur la fonction du poème comme sentence, non seulement éthique, mais surtout juridique, on relèvera simplement qu'en opposition à la loi hybristique du plus fort (pròs kieíssonas, vers 210) énoncée par l'épervier au terme de l'aînos qui lui est consacré, le locuteur-narrateur indique le chemin "plus fort » (kreísson, vers 217) qui conduit aux actes justes et qui permet finalement (es télos, vers 218) au droit d'avoir le dessus sur l'excès, sur l'büibris. De même qu'Épiméthée dans le récit de Pandôra ne réalisa son erreur (enóese, vers 89) qu'une fois le mal accepté, de même le naîf (népios, vers 218; voir vers 40) ne reconnaît son errement (égno, vers 218) qu'en subissant le triomphe de la justice. Et en contraste avec le terme entrevı pour l'âge de fer, marqué par le retrait sur l'Olympe de Pudeur et d'Indignation, cette victoire présente du droit signifie la présence de Serment et Justice; elle signifie aussi l'épanouissement de la cité (pólis, vers 227) à l'écart de la guerre sur une terre qui produit des récoltes abondantes (polìn bion, vers 232), sous le regard justicier de Zeus. Cet état de floraison et de profusion pacifiques évoque à nouveau l'âge d'or ${ }^{42}$; il s'oppose de manière d'autant plus forte et explicite à l'état annonçant l'éventuelle disparition des hommes de fer qu'il est notamment caractérisé par la ressemblance entre enfants et parents (vers 235), elle-même brouillée au terme prophétisé de l'âge de fer (vers 182) ! Les trois récits assument bien une fonction sémantique et argumentative dans le poème conçu comme sentence.

Mais l'institution de la production abondante d'un quasi-âge d'or par le règne de la justice sous le contrôle de Zeus requiert un intermédiaire. La médiation entre l'isotopie de l'administration de la justice et l'isotopie de la production du bios est en effet assurée par la parole efficace : parole de Zeus qui est prié d'édicter (íthune, vers 9) les règles du droit coutumier dans le

42 Pour les affinités de cet état de floraison privilégiée avec l'âge d'or, voir le commentaire de West (1978), p. 214-216; cf. aussi Crubfluier (1996), p. 462-463. 
prologue pour " redresser le courbe » (ithünei skolión, vers 7); parole qui doit trancher le conflit opposant le locuteur-narrateur à Persès par de droites sentences (itheíeisi dikeis, vers 36), dans la partie introductive du poème; voix (phonoén, vers 79) prononçant des récits trompeurs et mensongers, attribuée à Pandôra mais refusée aux maux qu'elle provoque; mots courbes (muithoisin skoliôts, vers 194) et faux serment lancés par le mauvais à la tête du meilleur pour le déconsidérer à l'occasion du brouillage des relations sociales survenant au terme prophétique de l'âge de fer; parole (mâthon, vers 206) d'autorité violente de l'épervier de la fable à l'égard du rossignol-aède; retour enfin, dans l'appel à la justice adressé à Persès, de Serment et de Diké pour redresser les sentences courbes (skoliêisi díkeisin, vers 219 et 221, puis vers 225-226, 230, 250, 258, 262, 263-264 et 280 !) et assurer par conséquent la prospérité de la pólis

Traversant comme troisième isotopie toute cette première partie du poème, la parole d'autorité est d'abord celle du poète, prudemment affirmé dans son pouvoir face à Zeus au terme du proème (vers 10). La voix d'autorité du poète est susceptible, par le poème lui-même, de régler "ce conflit" (ténde dikenn, vers 39). Díke désigne à la fois le contentieux juridique présent, historique, qui oppose le poète Hésiode à son frère Persès, et le déploiement de la justice tel que le poème le décrit (tênde díkenn, vers 249 et 269) à l'intention des rois. Sentence pour le conflit présent, le poème élargit son champ d'action à la cité en général, dans l'oscillation entre la référence extradiscursive et la référence intra-discursive que permet l'usage du déictique bóde tel qu'on l'a décrit au terme du $\$ 2^{\text {if }}$ ! De la situation particulière (extradiscursive) qu'offre le conflit avec Persès, le poème étend le domaine d'application de la justice à l'espace et au temps « universels » de la pólis idéale, de la pólis fictionnelle créée dans le poème.

La voix du poète lui-même est donc susceptible de faire alterner les développements positifs ou négatifs de l'équilibre juridique non seulement comme invitations adressées à Persès (vers 213 et 274 en structure annulaire) ou comme injonctions données aux rois (vers 248 et 263, aussi en structure annulaire), mais également sous la forme d'avertissements généraux, en tant que on- ou tu-vérités. C'est au nom de ces principes que les rois sont appelés à redresser leurs discours (ithunete muthous, vers 263$)^{45}$. On parvient ainsi au

i3 Aux vers 252-253, les "trois fois nombreux gardiens immortels » qui assistent Zeus dans la surveillance des actes et des sentences prononcées par les mortels évoquent les gardiens epikhthónioi (vers 122) que sont devenus, par la volonté de Zeus, les hommes d'or; WEST (1978), p. 181-183, 219-220 et 223-224, donne une série de parallèles indo-européens à ces figures divines de surveillants de mortels tout en indiquant une probable interpolation entre ces deux passages.

${ }^{4}$ Selon les indications données notamment par FeLSON (1999), p. 1-4, en particulier à la suite du linguiste allemand Karl Bühler qui montre les cas de combinaison possible entre demonstratio ad oculos et Deixis am Phanlasma (cf. supra n. 9).

${ }^{45}$ La structure complexe de cette partie consacrée à la leçon de justice tirée des trois récits est analysée par HANHTON (1989), p. 53-66; voir aussi Wfst (1978), p. 49-51 (sur le texte du vers 263, cf. [1978], p. 222), et CALANE (1996b), p. 185-189. 
terme de la première grande partie du poème, consacrée à la justice et démarquée du long développement dédié au travail et au bios par une nouvel appel à Persès au vers 286, par l'intermédiaire d'un futur performatif (eréo). En ce terme provisoire, le poète finit par assumer lui-même l'espoir (éolpa, vers 273) resté au fond de la jarre de Pandôra : l'espérance subsiste en effet que s'accomplisse malgré tout la justice de Zeus (telein au vers 273 , en écho à es télos au verra 218). Après une nouvelle affirmation de l'interdépendance de la parole de justice et du bonheur (ólbos, vers 281) par la volonté de Zeus, cette partie s'achève comme le récit des cinq âges sur un futur à portée prophétique, sinon oraculaire: la descendance (geneé, vers 284) du parjure s'effacera alors que celle de l'homme fidèle au serment (encore geneé au vers 285 !) connaîtra davantage de prospérité ${ }^{-46}$ !

En effet si quelqu'un entend prononcer en connaissance de cause de justes sentences, puisse Zeus au large regard lui conner la prospérité.

Mais celui qui volontairement appuie de faux témoignages

sur le parjure et qui blessant la justice commet une faute irréversible, laissera après lui une postérité qui ne fera que s'amoindrir.

La descendance de l'homme fidèle à son serment s'accroîtra.

De là l'efficacité de la parole poétique susceptible, de même qu'une prophétie, de rétablir l'ordre contrôlé par Zeus, en tant qu'intermédiaire entre la dike et le bios, entre l'équilibre de la justice et la prospérité matérielle et morale. En s'achevant sur un futur dynamique, la conclusion de la première grande partie des Travaux reprend dans sa mise en discours le mouvement temporel du récit de la succession des cinq espèces d'hommes. Dans cette mesure, le lógos des âges ne referme pas sa propre temporalité sur elle-même; son mouvement narratif ne clôt pas le temps raconté en un cercle. Mais comme c'est le cas pour les deux autres récits de la triade narrative, cette temporalité dynamique ordonne les espèces précédentes en une ligne à valeur argumentative, une ligne pragmatique qui en rend la leçon active dans le présent de l'énonciation. Parénèse ouverte sur le futur proche du temps social, la leçon de justice tirée des récits inscrit les Travaux dans le grand genre de la poésie didactique ${ }^{47}$. De là le double appel lancé à Persès par la voix d'autorité du poète, soutenu par Zeus, à écouter la leçon de la justice (vers 275), puis à travailler (vers 299), dans le futur immédiat!

\section{Les aléas du « comparer l'incomparable »}

Les différents indices énonciatifs qui structurent le poème des Travaux dans ses deux grands volets pointent à l'évidence vers la situation historique d'énonciation de ces vers hexamétriques en diction épique; l'énoncé de

46. WEST (1978), p. 228-229, a relevé la valeur oraculaire de l'emploi de l'adverbe metópisthe, "à l'avenir », aux vers 284 et 285 . On remarquera aussi l'usage du terme geneé, "la génération " et non plus génos, "l'espèce ", de même que dans le passage de l'âge du bronze à la période des héros (vers 160) : cf. supra n. 26.

47 Voir, à ce propos, les indications données par Neschke (1996), p. 477-478 (avec n. 22). 
l'énonciation pose la question de leur contexte extra-discursif. Les indices énonciatifs mentionnés renvoient en particulier au conflit opposant le locuteur, que la sphragís de la Théogonie permet d'identifier avec Hésiode, à son frère Persès. Ces deux figures apparaissent dès lors non plus comme des fabrications textuelles occupant des positions actantielles et énonciatives particulières, mais elles correspondent à des " personnes» historiques, douées de l'identité civile et civique que confère un nom propre et impliquées dans une situation familiale singulière que d'autres indices permettent d'entrevoir ${ }^{48}$. Par ses facultés fictionnelles, le poème a sans doute transformé une contestation historique autour d'un héritage dans une cité particulière en une situation générale valable pour toute pólis où le pouvoir de l'arbitrage juridique est aux mains de « rois » qui représentent sur terre l'autorité de Zeus ${ }^{49}$. À la faveur de cette transformation, le je du locuteur correspondant à Hésiode est devenu un aède dont la voix a une autorité pédagogique et prophétique particulières tandis que le $t u$-Persès se transformait dans le destinataire générique propre aux différentes formes grecques de la poésie didactique ${ }^{50}$. Le passage de l'intra- à l'extra-discursif nous renvoie donc en définitive, au-delà de l'instance de discours (et de son «partenaire »), aux règles du genre poétique, souvent ignorées en ce qui concerne les Travaux. Piste pour une autre enquête qui devrait de plus proposer une relecture de nos maigres informations sur le développement historique, institutionnel et social de la pólis, de la communauté politique entre vIII et viI ${ }^{e}$ siècles.

\subsection{Incursions comparatistes entre références indo-euro- péennes et sémitiques}

Pour qui aimerait enrichir la lecture d'un texte hellène dont la distance temporelle et culturelle a largement effacé l'univers de référence subsiste, proposée à l'origine par l'anthropologie historique et sociale, la voie comparatiste; avec deux pistes privilégiées pour la Grèce «archaïque » : la référence indo-européenne et la référence sémitique.

À l'écart des filiations historicisantes dont les Geisteswissenschaften du XIX ${ }^{e}$ siècle étaient friandes, on a désormais admis que le monde indo-européen n'est qu'une reconstruction savante et Georges Dumézil a lui-même fini par reconnaittre que les trois grandes «fonctions » correspondant dans les sociétés de la «famille » indo-européenne à des institutions et à des statuts particuliers n'ont de réalité que d'ordre idéologique. Ce report de la structure triadique de la réalité sociale sur le plan symbolique est à même d'entraîner une attitude de scepticisme vis-à-vis du tracé d'hypothétiques filiations historiques et

Cf. supra n. 4, avec les réflexions complémentaires sur la figure d'« Hésiode » dans CALAME (2000), p. 96-100 (avec les n. 20 et 23).

49 On trouvera en particulier chez CARRIËRE (1986), p. 229-236, une tentative de reconstruction du contexte historique et social relatif à la politique de l'établissement de la justice par l'abondance de la production prônée clans les Travaux:

50 La visée à la fois clidactique des Travaux dans le rétablissement de la justice sous le contrôle de Zeus a été fort bien explicitée par NAGY (1990a), p. 63-74. 
d'engager la démarche comparative dans la pure synchronie. Il s'agit là du parti de prudence choisi par Jean-Pierre Vernant quand il tente de référer aux trois fonctions de la souveraineté, de la guerre et de la fécondité les trois couples de « races » préalablement opposées, voire divisées pour être réorganisées en paires d'ordre structural ${ }^{51}$. Il n'a pas fallu trop d'astuces narratologiques aux relecteur's du récit des cinq espèces envisagé dans cette perspective du comparatisme européen pour montrer par exemple que le récit irlandais de la succession catastrophique des cinq races rapporté dans le Livre des conquêtes de l'Irlande ne présente aucune homologie, ni logique ni sémantique, avec le récit hésiodique. Par ailleurs, à l'égard du récit grec lui-même, on a constaté qu'il faut "déployer beaucoup d'ingéniosité » pour assigner les hommes d'argent avec leurs violences réciproques à la première fonction, celle de l'exercice du pouvoir religieux et royal, pour situer les héros et leur survie sous le chapeau de l'unique fonction militaire ou pour n'attribuer à la famille de fer, en la dédoublant, qu'une fonction de production ${ }^{52}$. En procédant à une assimilation de chacun des couples (supposés) de « races» à chacune des fonctions du modèle idéologique indo-européen, on oublie trop vite la position de charnière qu'occupe l'espèce de fer entre la succession narrative avec l'éventuelle institution génétique des trois fonctions et la situation finale où se situe le locuteur et poète lui-même. Si l'on se place dans lá perspective structurale qui rend compte d'un état complexe par sa généalogie, la famille de fer devrait impliquer simultanément, en ce carrefour narratif et énonciatif avec sa fonction temporelle, la fonction de production et l'ensemble du paradigme triadique!

À vrai dire, si l'on consent à travailler en pure synchronie en oubliant d'éventuelles relations génétiques, c'est à marquer les différences et les contrastes que la comparaison peut constituer une méthode de lecture enrichissante et méthodologiquement saine, en évitant des analogies dont seules généralité et abstraction peuvent assurer l'éventuelle pertinence ${ }^{53}$.

Dans cette perspective, la référence sémitique serait-elle plus productive? Dès le début du siècle dernier, les hellénistes ne sont pas restés insensibles aux nombreux récits qui, dans les cultures du Moyen-Orient, mais aussi en Inde ancienne, mettent en scène une confrontation narrative ou descriptive entre métaux de valeur différente au service d'une distinction entre différents états sociaux. Parmi ces récits, celui qui évoque au plus près le lógos hésiodique est sans conteste le récit du rêve de Nabuchodonosor tel que le raconte dans l'Ancient Testament le Livie de Daniel. La narration présente tous

51 La naissance et le cléveloppement du concept d'uindo-européen » en concomitance avec celui d'«aryen » sont retracés en particulier par OLENDER (1989), p. 26-38; voir aussi BERNAL (1996), p. 277-286 et 385-442. Pour le statut de l'«idéologie " indo-européenne, voir DumézIL (1968), p. 46-53 et 493-496 (pour la Grèce); en ce qui concerne en particulier le récit hésiodique des cinq espèces, cf. VERnant (1966), p. 43 n. 103.

52 CAlRrière (1986), p. 218-226 avec n. 66.

${ }^{53}$ Pour la question du comparatisme à aborder dans la perspective de la traduction transculturelle, cf. CALAME (2002), p. 67-77. 
les caractères énonciatifs du récit au passé tout en donnant un repère chronologique et une référence spatiale précises. Même si la statue mise en scène dans le récit pourrait trouver un référent historique dans la période d'exil du peuple juif en correspondance avec l'indice chronologique donné par le texte lui-même, il semble que, reposant sur un récit de tradition orale, la rédaction de cette partie du Livre de Daniel ne remonte qu'au milieu du II $^{e}$ siècle av. J.-C $\mathrm{C}^{55}$.

\subsection{Daniel et le rêve vétéro-testamentaire de Nabuchodo- nosor}

Ainsi, la deuxième année du règne du souverain de Babylone (qui correspond à environ 604 avant l'ère chrétienne), le jeune Daniel fut emmené à la cour du roi avec d'autres jeunes Judéens qui se distinguaient par leur savoir et leur intelligence pour être confronté aux songes qui troublaient le sommeil de Nabuchodonosor. Substituant à l'incapacité des magiciens et devins chaldéens la sagesse et la science inspirées par le Dieu d'Israël, Daniel parvint à remplir le vou paradoxal du roi de Babylone, à savoir deviner le songe lui-même avant d'en donner l'interprétation correcte. Se réclamant de l'autorité de Dieu, Daniel raconte donc lui-même le songe de la statue brillante et terrible dont la tête est d'or, la poitrine et les bras d'argent, le ventre et les cuisses de bronze, les jambes de fer, et les pieds à la fois de fer et de terre cuite. En détruisant ses pieds fragiles, un rocher contribue à l'écroulement de la statue dont tous les éléments sont dispersés par le vent, ne laissant dressée que la montagne née du rocher destructeur. Dans l'interprétation historicisante du rêve donnée par Daniel, la tête d'or est assimilée à Nabuchodonosor lui-même qui, par la volonté du Dieu du Ciel, règne sur toute l'humanité, avec pouvoir, force et gloire. Les parties du corps deviennent, dans un passage du synchronique au diachronique, des royaumes qui se succèdent, dans un ordre de progressive décadence, avant que l'agglomération du fer et de l'argile ne marque l'avènement d'un règne en proie à la division. Ce règne ultime sera détruit et remplacé de manière définitive par la montagne renvoyant au royaume étenel du Dieu même qui, tout en anéantissant à jamais tous les règnes précédents, est aussi le garant de la véracité du rêve et de la pertinence de l'interprétation !

Sans entrer dans les détails d'une construction discursive et énonciative pour le moins complexe, on remarquera qu'au-delà de quelques analogies se limitant à la succession des métaux, le récit de l'Ancien Testament présente un temps raconté et par conséquent une narration qui sont axés sur un moment chronologique précis (l'an II du règne de Nabuchodonosor) et sur un point géographique défini (Babylone, la capitale et résidence du roi); dans cette

54 Dan. 2, 1-3, 7, signalé par ReITZENSTEIN (1924/5), p. 525-527, puis repris notamment par WEST (1997), p. 312-319, qui justifie les relations du «Myth of Ages " d'Hésiode avec différents textes orientaux en affirmant de lui : «Its very formulation is un-Greek » (312) !

55 Les conditions de rédaction du récit vétérotestamentaire et la question de sa date font l'objet de l'étude équilibrée de LAcocque (1983), p. 66-79. Merci à Thomas Römer pour cette utile indication bibliographique. 
mesure, le récit biblique s'oppose au récit hésiodique des cinq familles qui, au lieu de bénéficier d'un repérage spatio-temporel d'ordre historique, est au contraire orienté sur le bic et nunc de l'énonciation, un bic et numc qui n'est repéré ni du point de vue temporel, ni du point de vue spatial. Le récit biblique est donc traversé par une temporalité dont l'orientation présente l'exact inverse du temps discursif construit dans le récit hésiodique. C'est que, énonciativement, la narration décrivant la statue avec son destin ainsi que le récit interprétatif qu'elle suscite ne sont pas assumés directement par un locuteur-narrateur inspiré par la Muse; mais tous deux sont mis dans la bouche de l'un des protagonistes d'un récit rédigé à la troisième personne et marqué par des repères chronologiques et géographiques de type historique, à l'écart de toute intervention énonciative explicite. Inséré dans une narration énonciativement anonyme, le double récit concernant la statue aux quatre métaux (auquel s'ajoute l'argile) est donc prononcé par le sage étranger qui intervient à la cour de Nabuchodonosor. Mais dans sa narration insérée et par conséquent mimétique, le jeune Daniel est inspiré par le savoir de Dieu qui lui est révélé dans une vision préalable à sa confrontation avec le roi de Babylone. Indirecte, l'instance d'énonciation sous-jacente au récit de la statue et à son interprétation est donc dédoublée: elle correspond d'une part au "Dieu du Ciel » reconnu par les Hébreux du royaume de Juda, et d'autre part à l'un des jeunes gens choisis par le roi de Babylone pour recevoir une éducation savante; ils sont doués par le dieu d'Israël d'une intelligence et d'un savoir supérieurs, en particulier dans le domaine de l'interprétation des songes.

La demande imposée par le roi, dans le récit encadrant l'intervention de Daniel, de deviner son propre rêve avant d'en donner l'interprétation correcte place par ailleurs la structure avant le détoulement temporel : d'abord les cinq règnes (et non pas des gêne, des espèces d'hommes) dans l'ordre synchronique et hiérarchique que leur assignent autant la valeur relative du métal correspondant que leur situation respective dans le corps de la statue, puis l'intervention narrative du rocher qui, après avoir réduit en poussière simultanément toutes les parties de la statue, se métamorphose en montagne. Ce renversement narratif confère au récit interprétatif qui fait suite sa dynamique temporelle, en transformant l'ordre taxinomique donné par la description des parties de la statue en une succession de royaumes de plus en plus fragiles. Cette séquence débouche sur l'institution du règne éternel du "Dieu du Ciel » qui correspond au dieu ayant donné à Daniel le savoir et l'inspiration à l'origine du récit herméneutique lui-même.

Contrairement à ce qui se passe dans le texte hésiodique, le présent (narratif) de l'énonciation énoncée du récit biblique prononcé par Daniel est marqué par une adresse préalable au roi de Babylone tout en étant d'emblée placé sous l'autorité du Dieu d'Istaël : «Le mystère que poursuit le roi commence Daniel - sages, magiciens, devins et enchanteurs n'ont pu le découvrir au roi : mais il y a un Dieu dans le ciel, qui révèle les mystères et qui a fait connaître au roi Nabuchodonosor ce qui doit arriver à la fin des 
jours. Ton rêve et les visions de ta tête sur ta couche, les voici ». Ce repérage spatio-temporel d'ordre énonciatif coïncide non pas avec le terme, mais avec le début, avec le moment axial du temps raconté : la tête de la statue, c'est non seulement la tête du roi en proie à des visions, mais c'est surtout le royaume d'or et par conséquent le règne de Nabuchodonosor lui-même. Les règnes successifs sont dès lors présentés dans un futur interprétatif et prophétique qui les conduit, dans une adéquation entre temps de la narration et temps narré, à la destruction finale; destruction qui marque, avec l'avènement du royaume de Dieu sur terre, l'institution d'un deuxième point axial. En raison de son caractère permanent et terrestre, en raison aussi de la coincidence entre celui qui le domine et celui qui par la bouche du sage Daniel le révèle, le temps narratif du règne du «Grand Dieu » englobe le temps de l'énonciation tout en lui donnant son sens.

À la faveur de cet enchâssement temporel, le royaume futur et divin du Dieu unique des Judéens se substitue à l'âge d'or du règne présent et humain comme point de référence spatio-temporel; viennent y converger les différents niveaux discursifs et les différentes lignes spatio-temporelles du récit biblique. À une focalisation sur le temps de l'énonciation et sur les effets de la parole poétique s'est substituée une perspective téléologique centrée sur le règne atemporel et universel d'une instance divine. Rien de plus étranger à la poétique de la Grèce «archaique »; rien de plus exotique pour des Grecs constamment préoccupés autant par la réalisation de leur mortalité dans un temps terrestre sans finalité et soumis à des renversements de fortune aussi brusques qu'imprévisibles; rien de plus éloigné du souci hellène pour une forme de survie dans un monde de bonheur situé à l'écart du séjour des dieux olympiens, aux confins de la terre habitée.

\section{Le bic et munc d'un poème didactique}

Quelles que soient les multiples voies de transmission qu'on a pu imaginer récemment pour tenter de référer les manifestations symboliques des Grecs des VIII" et VII ${ }^{e}$ siècles à différentes influences " orientales », ni la date du texte biblique, ni l'idéologie qui le traverse ne permettent d'établir le moindre contact, sans même parler de filiation, avec le texte hésiodique ${ }^{56}$. Au lieu d'affirmer que "the myth appears entirely alien to the general Greek view of the past as reflected in the whole corpus of epic and genealogical poetry », l'étude de la structure spatio-temporelle du récit des cinq espèces d'hommes révèle dans la succession de leurs qualités spécifiques ce qui a été perçu à juste titre comme une « historicisation » progressive ${ }^{57}$. En effet, si la description

56 Ceci en dépit des affimations lénifiantes de WVST (1997), p. 2-4 et 586-624, qui dans son grand travail comparatif affirme s'intéresser aux parallèles offerts clans les formes de l'expression des textes anciens de l'" Asie occidentale » pour rejeter délibérément les différences.

57 Voil en particulier CARRtère (1996), p. 411-418, ainsi que, de manière beaucoup plus floue, MOST (1997), p. 121-127, et BALlabigigs (1998), p. 329-339, dont l'hypothèse "historicogénétique » est pour le moins contestable. 
des violences commises par les hommes de bronze évoque le vocabulaire même qui qualifie souvent les héros de l'fliade en rapport avec leur insertion partielle dans un «âge de bronze» poétique, la mention des héros de l'épopée morts sous les murs de Troie ou de Thèbes évoque les honneurs cultuels dont certains d'entre eux étaient l'objet sans doute à l'époque même d'Hésiode. Ce rapprochement temporel progressif à l'égard de la réalité historique du "maintenant» de l'énonciation va de pair avec une spatialisation d'ordre géographique : les héros sont situés dans un espace grec, à Thèbes et à Troie, avant que le futur réorienté par le poème offre à nouveau un cadre spatio-temporel à valeur « universelle», valable pour toute pólis (grecque...) soumise à l'ordre olympien de Zeus et bénéficiant de la prospérité assurée par l'équilibre de la justice.

À l'écart de toute tentative de division des périodes occupées par chaque génos et d'articulation de ces entités en oppositions binaires, ce qui frappe dans le déroulement du temps raconté dans le récit des cinq âges, c'est l'alternance entre périodes fastes de proximité avec les dieux et pétiodes de violence impie $\mathrm{e}^{58}$. Cette conception du temps social et historique des hommes mortels n'est pas sans rappeler la fameuse déclaration d'Hérodote mettant son Enquête sous le règne de l'alternance du bonheur et du malheur qui frappent, sous le signe de la dike et de la buibris, de la justice et de la rupture de son équilibre, les cités des hommes aussi bien que les hommes eux-mêmes. Mais elle évoque aussi, plus près de la tradition poétique dans laquelle s'inscrit Hésiode, l'image de la caducité du feuillage utilisée par Glaucos face à Diomède dans l'zliade pour illustrer la succession des générations des hommes mortels ${ }^{59}$ ! Ce rythme d'alternance de prospérités et de maux combiné avec une succession de naissances et de disparitions est beaucoup plus prégnant qu'une succession réorganisée en oppositions binaires. Il est l'une des composantes essentielles de la condition de l'homme mortel, en relation avec les Olympiens et plus particulièrement avec Zeus, telle qu'elle est définie par les trois récits des Travaux: avant d'être décrite par le poète lui-même.

Si la condition même du mortel interdit tout retour cyclique à l'âge d'or, en revanche le récit du passé des hommes jusqu'en son point d'origine situé en

58 Cette alternance a été ressentie tour à tour par CARRÈre (1986), p. 226-229, qui propose d'organiser la succession des espèces humaines selon un axe temporel à figure sinusoïdale, par COULOUBARITSIS (1996), p. 500-507 et 517, qui imagine une temporalité narrative organisée selon un rythme hélicoïdal, ou par MOST (1997), p. 108-114, qui tente de voir dans le récit d'Hésiode la combinaison de trois schèmes: $1+1+3,1+1+2+1,1+1+1+2 \ldots$; voir aussi Crubelljer (1996), p. 453-455, qui reste malgré tout attaché à l'image temporelle cyclique ! S'il faut choisir un modèle d'organisation, on pourra se limiter à le repérer dans le développement sémio-narratif du récit : selon la logique proposée par le "schéma canonique », le statut des hommes d'or et d'argent pourrait correspondre à la phase de la manipulation narrative, puis l'action des hommes de bronze et surtout celle des héros évoqueraient la phase de compétence qui recevrait sa réalisation et performance dans l'âge de fer avec la sanction que représente le futur prophétique énoncé par la voix du poète.

59) HDT., I, 5, 3-4; HOM., Il. VI, 145-149; on trouvera des références complémentaires chez CALAME (2000), P. 85-86. 
un autre temps de même que l'évocation du destin post mortem connu par la génération (et non plus l'espèce : genée et non plus génos) précédente des héros en un espace des confins renforcent le pouvoir de la parole du poète. Parcours temporel et incursion spatiale sont, en effet, mis au service d'une voix poétique qui, soutenue par les Muses et inspirée par Zeus, entretient l'espoir d'une action juridique. Dans son élargissement poétique, cet acte de justice installera la communauté civique, par le développement des ressources vitales, dans un état proche des béatitudes quasi divines connues soit par les hommes d'or, au début de l'histoire des hommes, soit par les héros, aux confins de la terre. À l'écart de toute conception cyclique du temps, il s'agit de réorienter le futur, grâce à la force de la parole épique et didactique et par référence à un double paradis perdu ${ }^{\text {(n) }}$. Seuls justice et travail peuvent faire coïncider, dans une temporalité éphémère, l'« ici » de la cité avec ce double ailleurs, proche du domaine habité par les dieux. Par les moyens du renversement et de la dérision comiques, les propositions sociales formulées dans les comédies de la première partie de la carrière d'Aristophane ne sont en somme pas très différentes: des Achamiens à la Paix, l'utopie civique mise en scène dans le théâtre de Dionysos devant les citoyens assemblés se réfère à un âge d'or qui ne peut être réalisé que par le fonctionnement ordonné des institutions proprement humaines fondant l'âge de fer, soit le mariage, le sacrifice et le banquet ${ }^{61}$ !

Cet ailleurs social et temporel à réaliser, provisoirement au moins, ici et maintenant, dans l'ordre civique garanti par Zeus, peut aussi être atteint après la mort, par des pratiques verbales et rituelles que l'on évoquera au dernier chapitre du présent essai. Quoi qu'il en soit, ce lieu et ce temps de l'utopie civique n'ont rien à voir avec le royaume de Dieu institué ici-bas comme le suggère la comparaison avec le texte biblique. Mise en garde contre une méthode comparative hâtive qui ne porte que sur des analogies narratives et thématiques sans se préoccuper des effets de sens dans des contextes culturels et historiques singuliers. Plaidoyer également et de manière plus positive pour une approche sensible aux catégories "indigènes » tout en rappelant la dimension forcément triangulaire d'un tel cheminement: aux contrastes notionnels que fait apparaître la confrontation entre deux cultures " exotiques » différentes s'ajoute la conscience que la perspective comparante de l'anthropologue lui-même, aussi dialogique qu'elle se prétende désormais, ne peut être qu'interprétative ${ }^{62}$ : les catégories des "natives " ne peuvent ètre perçues et reformulées qu'au travers d'une délicate opération de traduction, marquée culturellement dans l'espace et dans le temps tant il est vrai que

G) Cf. CARrzère (1991), p. 100-105; "L'âge d'or est une garantie mythique de prospérité pour les justes d'aujourd'hui " (101); voir aussi Brown (1998), p. 401-409, pour des parallèles pertinents.

61 Voir à ce propos les conclusions formulées par AUGER (1979), p. 72-89.

62 Différents aspects du défi que représente du point de vue de la traduction des concepts une anthropologie qui se veut désormais dialogique sont exposés en patticulier par BoRUTTI (1999), p. 171-202, et par FABIETTI (1999), p. 57-71 et 227-251. 
notre propre culture (académique) est elle-même soumise au changement historique et conceptuel. Le constat des limites que le temps a imposées au paradigme structural doit nous engager à beaucoup de modestie à l'égard du paradigme dont nous pouvons nous réclamer, tant il est vai qu'il est lui aussi soumis à l'inexorable travail du temps !

Mais au-delà de la brève leçon de méthode, le caractère didactique de la parole poétique des Travaux nous invite lui-même à lire dans le déploiement des engagements prodigués par Hésiode une autre invitation; elle concerne plus précisément nos propres relations avec nos représentations du passé. Nûn gàr dê gênos estî sidêreon, "c'est maintenant précisément l'espèce de fer" (vers 176), psalmodie l'aède qui récite les Travaux au moment où il intervient dans son propre récit pour en orienter le cours temporel dans le sens de la prophétie. Dans cette mise en relation énonciative du passé avec le présent, Hésiode se fonde sur ce qui deviendra une constante de l'historiopoiétique grecque, aussi bien dans ses versions poétiques que dans ses formes plus historiographiques. La manière qu'a Hérodote de référer au présent et à son propre temps (es'eme) les événements narratifs du passé récent qu'il rapporte ou qu'il reformule dans son lógos procède de ce souci permanent - on l'a déjà signalé. Du côté de la poésie épique, on pourrait ajouter, à l'époque hellénistique, l'utilisation que fait Apollonius de Rhodes des tombes héroïques comme indices (sếma) de la relation temporelle unissant le passé épique avec ce qui perdure «là maintenant encore» (énth' éti nuin per); et, beaucoup plus tard, c'est encore ce souci de la relation d'un passé héroïque originaire avec le présent de la Grèce romanisée qui anime la constante perspective étiologique de l'itinéraire proposé par Pausanias dans les lieux de mémoire et dans l'histoire religieuse de la Grèce continentale ${ }^{63}$. Cette perspective étiologique est d'ailleurs déjà implicitement présente dans le récit hésiodique des cinq âges ${ }^{6 / 4}$ : l'état actuel de rupture de l'équilibre de la justice dénoncé par le poète ne peut s'expliquer que par les abus commis par les espèces humaines précédentes.

À travers les siècles et par les moyens de la poésie hexamétrique didactique, la voix d'Hésiode nous adresse encore un double rappel: invitation à écarter les formes les plus désengagées de la «micro-histoire », mais aussi appel à rejeter le nominalisme auquel revient une histoire réduite à de simples "formes d'écriture ". Non seulement notre propre relation à un passé que nous (re)configurons ne peut être qu'engagée dans un présent : le présent que, par les procédés fictionnels et rhétoriques de la configuration, nous

63 Pour Hérodote et Pausanias, voir les références données chez CALAME (2000), p. 164 n. 17 et 241 n. 77; pour Apollonius de Rhodes, voir par exemple I, 1058-1062 ou II, 714-719, en contraste avec le récit homérique où les protagonistes héroiques de l'action épique se réfèrent au présent de l'énonciation du poème comme à un temps à venir ! Cf. SAÏD (1998), p. 16-19.

6if Comme cela a été relevé par Brown (1994), p. 389 ("Put together, the past bad races account for the origin of the vices which Hesiod considers to be most prevalent among his contemporaries »).

${ }^{65}$ RANCIÈRE (1992), p. 207; sur la micro-histoire, voir les références critiques données par RICCEUR (2000), p. 267-280. 
contribuons à orienter. Mais cette relation elle-même est également, d'une manière ou d'une autre, animée par une causalité d'ordre explicatif qui devient motivation pour le présent. Dans cette mesure l'histoire qu'on appelle «sociale », en dépit des dénigrements dont elle a été récemment l'objet de la part du libéralisme postmoderne, a encore un bel avenir devant elle... Dans cette mesure aussi, le paradigme épistémologique dont nous dépendons dans des sciences humaines largement à la recherche d'approches nouvelles et (re)fondatrices ne conduit pas à la négation de ses prédécesseurs. Il s'agit non pas de nier les apports de l'analyse structurale, mais de dépasser les immanquables apories auxquelles aboutissent l'application du principe d'immanence et le travail en pure synchronie. En prenant en compte la dimension pragmatique de toute manifestation langagière, les moyens heuristiques offerts par l'analyse des discours permettent de restituer au texte, à l'écart de toute signification instituée comme «le » sens, son épaisseur de manifestation culturelle requérant une approche anthropologique, dans une herméneutique consciente de son historicité.

Claude CALAME

EHESS - Paris

\section{Bibliographie}

D. AUGER, "Le théâtre d'Aristophane: le mythe, l'utopie et les femmes ", in Aristophane, les femmes et la cité (Cabier's de Fontenay' 17), Paris, E.N.S., 1979: 71-101

A. BALlabriga, "L'invention du mythe des races en Grèce archaïque ", Revue de l'bistoire des religions 215 (1998), p. 307-339

M. BERNAL, Black Atbena. Les racines afro-asiatiques de la civilisation classique I. L'invention de la Grèce antique, 1785-1985, Paris, PUF, 1996 (éd. or. : Black Atbena. The Afroasiatic Roots of Classical Civilization I. The Fabrication of Ancient Greece : 1785-1985, London, Free Association Books, 1987)

F. Blaise, P. JudFt de LA COMBE, Ph. ROUSSEau (éds), Le métier du mythe. Lectures d'Hésiode, Lille, Septentrion, 1996

S. BORUTTI, Filosofia delle scienze amane, Le categorie dell'Antropologia e della Sociologia, Milano, Bruno Mondadori, 1999

A.S. Brown, "From the Golden Age to the Isles of the Blessed ", Mnemosyne 51 (1998), p. 385410

K. BüHLER, Spracblheorie. Die Darstellungsfunktion der Spracbe, Jena, Böhlau, 1934 (trad. angl. : Theory of Language: The representational function of language, Amsterdam/Philadelphia, Benjamins, 1990)

C. Calave, Mylbe el bistoire dans l'Antiquité grecque. La création sy'mbolique d'une colonie, Lausanne, Payot, $1996 a$

-, "Le proème des Travaux d'Hésiode, prélude à une poésie d'action », in Blaise, Judet de La Combe, Rousseau (éds), 1996b, p. 169-189

-, Poétique des mythes dans la Grèce antique, Paris, Hachette, 2000

-, "Interprétation et traduction des cultures. Les catégories de la pensée et du discours anthropologiques », L'Homme 163 (2002), p. 51-78

J.-C. CARrière, «Les démons, les héros et les rois dans la cité de fer. Les ambiguïtés de la justice dans le mythe hésiodique des races et la naissance de la cité ", in Lire les polythéismes I. Les 
grandes figures religieuses, Besançon/Paris, Faculté des Lettres/Belles Lettres, 1986, p. 193261

-, «Mystique et politique dans Les Travanx ef les Jours d'Hésiode. L'authenticité et les enjeux du vers 108 ", in Mélanges Étienne Bernand, Besançon/Paris, Faculté des Lettres/Belles Lettres, 1991, p. 61-119

-, «Le mythe prométhéen, le mythe des races et l'émergence de la Cité-État », in BLAISE, JUDET DF LA COMBE, ROuSSEAU (éds), 1996, p. 431-463

P. Chantraine, Dictionnaire étymologique de la langue grecque. Histoire des mots, Paris, Klincksieck, 1968

L. COUloubaritsis, "Genèse et structure dans le mythe hésiodique des races ", in BLAISE, JUDET DE LA COMBE, ROUSSFAu (éds), 1996, p. 497-518

M. CRUBeluIER, «Le mythe comme discours. Le récit des cinq races humaines dans Les Travaux et les Jours ", in BLAISE, JUDET DE LA COMBE, ROUSSEAU (éds), 1996, p. 431-463.

C. Darbo-Peschansk, «Fabriquer du continu (l'historiographie grecque face au temps)», Storia della storiografia 28 (1995), p. 17-34

G. DuMÉzIL, Mythe et Épopée I. L'idéologie des trois fonctions dans les épopées des peuples indoeuropéens, Paris, Gallimard, 1968

U. FABIETT, Antropologia culturale L'esperienza e l'interpretazione, Rona/Bari, Laterza, 1999

N. Felson, «Vicarious Transport: Fictive Deixis in Pindar's Pytbian Four", Harvard Studies in Classical Pbilology 99 (1999), p. 1-31

V. GOLDSCHMDT, "Theologia », Revue des Etudes Grecques 63 (1950), p. 20-42 (repris in Questions platoniciennes, Paris, Vrin, 1970 , p. 141-159, avec un «Addendum », p. 159-172)

M. HALBWACHS, Les cadres socianx de la mémoire, Paris, Alcan, 1925

R. HamiLton, The Architecture of Fesiodic Poety, Baltimore/London, The Johns Hopkins University Press, 1989

M.-Chr. LECLERC, «Le mythe des races. Une fiction aux sentiers qui bifurquent », Kernos 6 (1993), p. $207-224$

G.W. MOST, "Hesiod's Myth of the Five (or Three or Four) Races ", Proceedings of the Cambridge Philological Association 43 (1997), p. 104-127

G. NAGY, The Best of the Achaeans, Concepls of the Hero in Arcbaic Greek Poelry, Baltimore/London, The Johns Hopkins University Press, 1979

A. NESCHKE, «Dikè. La philosophie poétique du droit dans le "mythe des races" d'Hésiode ", in BLAISE, JUDET DE LA CONBE, ROUSSEAu (éds) 1996, p. 465-478

M. OLENDER, Les langues du paradis. Alyens et Sémites : un coupe providentiel, Paris, Gallimard / Seuil, 1989

R. PARKer, Miasma. Pollution and Parification in Ealy Greek Religion, Oxford, Clarendon Press, 1983

P. Pucc, The Songs of the Sirens. Essays on Homer, Lanham/Boulder/New York/Oxford, Rowman \& Littlefield, 1998, p. 11-29

J. RANCIÈre, Les noms de l'bistoire. Essai de poétique du savoir, Paris, Seuil, 1992

R. REITZENSTEIN, "Altgriechische Theologie und ihre Quellen ", Vorträge der Bibliothek Warburg 4 (1924/5), p. 1-19, repris in E. HEITSCH (éd.), Hesiod, Darmstadt, Wissenschaftliche Buchgesellschaft, 1966, p. $523-544$

P. Ricceur, La mémoire, l'bistoire, l'oubli, Paris, Seuil, 2000

S. SAl̈, "Tombes épiques d'Homère à Apollonios », in S. MARCHEGAY, M.-Th. LE DiNAHET et J.F. SALles (éds), Nécropoles et powvoirs. Icléologies, pratiques el interprétations, Paris, de Boccard, 1998, p. 9-19

J.U. SCHMIDT, Adressat und Paraineseform. Zul. Intention von Hesiods Werken und Iagen, Göttingen, Vandenhoeck \& Ruprecht, 1986

Ch. Sourvinou-Inwoon, 'Reading' Greek Death. To the End of the Classical Period, Oxford, Carendon Press, 1995 
-, "The Hesiodic Myth of the Five Races and the Tolerance of Plurality in Greek Mythology ", in O. Palagia (éd.), Greek Offerings. Essays on Greek Ant in Honour of John Boardman, Oxford, University Press, 1997 (Oxford Monographs 89), p. 1-21

J.-P. VERNAN", "Le mythe hésiodique des races. Essai d'analyse structurale", Revue de l'histoire des religions 157 (1960), p. 21-54, repris in Wythe et pensée chez les Giecs. Etudes de psychologie bistorique, Paris, La Découverte, 1985², p. 19-47

--, "Le mythe hésiodique des races. Sur un essai de mise au point », Revue de Pbilologie 40 (1966), p. 247-276, repris dans ibid., p. 48-85

M.L. WEST, Hesiod. Theogony; Oxford, Clarendon Press, 1966

-, Hesiod. Works and Days, Oxford, Clarendon Press, 1978

-, The East Face of Helicon. West Asiatic Elements in Greek Poetry and Mytb, Oxford, Clarendon Press, 1997 